\title{
RDUS
}

Revue de DROIT

UNIVERSITÉ DE SHERBROOKE

Titre : $\quad$ LES ENJEUX DE LA RECEVABILITÉ DE LA PREUVE D'IDENTIFICATION PAR ADN DANS LE SYSTÈME PÉNAL CANADIEN

Auteur(s) : $\quad$ Marie Angèle GRIMAUD

Revue : $\quad$ RDUS, 1993-1994, volume 24, numéro 2

Pages: $\quad 293-345$

ISSN : $\quad 0317-9656$

Éditeur : $\quad$ Université de Sherbrooke. Faculté de droit.

URI : $\quad$ http://hdl.handle.net/11143/13372

DOI : https://doi.org/10.17118/11143/13372 
Page vide laissée intentionnellement. 


\title{
ARTICLE
}

\section{LES ENJEUX DE LA RECEVABILITÉ DE LA PREUVE D'IDENTIFICATION PAR ADN DANS LE SYSTÈME PÉNAL CANADIEN*}

\author{
par Marie Angèle GRIMAUD**
}

La lutte contre la criminalité repose de plus en plus sur des méthodes efficaces et modernes d'identification. L'une de ces méthodes fait appel à l'identification par ADN considérée comme un moyen récent pour découvrir la vérité. Dès lors, il paraît légitime d'examiner la pratique juridique qui, en l'absence d'un cadre normatif, peut susciter des inquiétudes non seulement au plan de l'application technique mais surtout à celui du respect des droits fondamentaux. Sans prêcher un positivisme «excessif», il nous semble que des modifications ou des ajustements à la législation actuelle sont souhaitables afin de favoriser l'intégration de cette preuve dans notre système juridique.

1. Ce texte est à jour au 30 juin 1994 et constitue une version élaborée du rapport de synthèse présenté en décembre 1992 dans le cadre du doctorat en droit de l'Université de Montréal.

2. Chargée de cours à la Faculté de droit de l'Université de Montréal, assistante de recherche au Centre de Recherche en Droit Public de l'Université de Montréal. L'auteure désire remercier vivement les professeurs Bartha Maria Knoppers, Pierre Patenaude, Louise Viau et le Docteur Léo Lavergne de la Direction des Expertises Judiciaires pour leurs commentaires commentaires. La rédaction de cet article a été rendu possible grâce à l'appui financier du FRSQ. 
The war on crime depends increasingly upon more effective methods of identification. One such method utilizes DNA typing as a means of deter-mining the truth. Accordingly, this technique merits legal scrutiny, considering the fact that the absence of a normative framework raises concerns not only as to its technical applications but also with regard to the protection of fundamental rights. Without going so far as to adopt a strongly interventionist posture, the writer argues that some changes to existing law are desirable in order to facilitate the integration of this type of evidence into our legal system. 
(1994) 24 R.D.U.S.

Les enjeux de la recevabilité

de la preuve d'identification par $A D N$

SOMMAIRE

INTRODUCTION

I- APERÇU TECHNIQUE DE LA MÉTHODE . . . . . . . . 301

A- $\quad$ Le substrat : I'ADN $\ldots \ldots \ldots \ldots \ldots \ldots \ldots \ldots \ldots \ldots$

B- Les techniques d'identification génétique ......... 304

1- $\quad$ Les méthodes d'analyse proprement dites . . ... 304

1.1. La méthode de Southern ........... 304

1.2. La méthode d'amplification ou $P C R \quad \ldots 305$

2- $\quad$ La fiabilité des méthodes d'identification génétique ..................... 307

2.1. Les nombreux avantages liés au carac-

tère intrinsèque du matériel utilisé . . . . . . . . 307

2.1.1. La facilité dans la cueillette des

éléments de preuve à cause de : . . . . . . 307

2.1.2. La simplicité de visualisation ... 308

2.1.3. La certitude d'appariement basée sur la concordance des échantillons

...................... 308

2.1.4. La force de probabilité de préci-

sion et d'individualisation ........... 309

2.1.5. La discrimination évidente . . . . 309

2.1.6. La rapidité des analyses ....... 310

2.2. Les problèmes potentiels . ........ 310

2.2.1. Les questions techniques ...... 310

2.2.2. Les questions d'expertise et d'interprétation ............. 311

II- LA RECEVABILITÉ DE LA PREUVE D'IDENTIFICATION PAR ADN EN DROIT PÉNAL CANADIEN ...... 314 A- État actuel de l'admissibilité de la preuve

d'identification par ADN . . . . . . . . . . . . . . . . 315

1- $\quad$ La théorie de Frye ................... 316

1.1. La théorie de l'acceptation générale scientifique ................... 316 
1.2. Le rejet de la théorie de Frye . . . . . . 317

2- $\quad$ La théorie de la pertinence ............ 318

2.1. La discrétion judiciaire ......... 319

2.2. L'impact de la Charte ........... 320

B- Critères de pertinence et d'utilité : critères élaborés

par la jurisprudence . . . . . . . . . . . . . . . 322

1- Utilité comme preuve matérielle et comme

témoignage d'expert ................. 324

2- $\quad$ Valeur probante de la preuve ........... 324

2.1. Probabilité et langage ........... 325

2.2. Preuve hors de tout doute raisonnable . . 326

\section{III- LA PREUVE D'IDENTIFICATION PAR ADN ET LES}

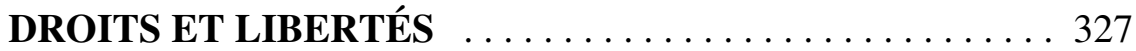

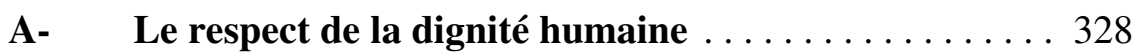

1- Les droits fondamentaux . . . . . . . . . 328

1.1. Le droit à l'intégrité . . . . . . . . . . 329

1.2. Le droit à la vie privée $\ldots \ldots \ldots \ldots \ldots 331$

1.2.1. La Conservation des échantillons

et la constitution des banques

de données ............... 332

1.2.2. Le droit à la confidentialité .... 335

1.3. Le droit à la non-discrimination . . . . . . 335

2- $\quad$ Les droits de la défense . . . . . . . . . . 336

B- $\quad$ Nécessité d'un encadrement . . . . . . . . . . . . . 337

1- Débat éthique et mécanismes de gestion sociale

......................... 337

1.1. Assises prospectives ........... 338

1.2. La communication ............. 340

2- $\quad$ Assises de droit positif . . . . . . . . . . . . 341

2.1. Droit comparé .............. 341

2.2. Proposition d'une législation au Canada 
Les enjeux de la recevabilité

(1994) 24 R.D.U.S. de la preuve d'identification par ADN dans le système pénal canadien 


\section{INTRODUCTION}

L'observation du système pénal met en évidence deux démarches complémentaires : d'une part, une vocation de justice et de maintien de l'ordre public et d'autre part, un objectif d'efficacité et d'intimidation (il faut réprimer et prévenir le délit ou le crime; c'est à dire ôter au criminel les raisons d'une récidive et «détourner les autres de suivre son exemple» ${ }^{1}$ ). Dès lors, la preuve ${ }^{2}$ acquiert une importance capitale dans le procès pénal, du fait qu'elle peut entraîner soit la condamnation, soit la relaxe ou l'acquittement. Les moyens de preuve utilisés sont nombreux, diversifiés et les méthodes s'affinent au fur et à mesure que la science avance. L'avènement des preuves dites scientifiques est relativement récent. De ce fait, ces nouveaux modes de preuve axés sur la science sont encore mal perçus par le monde juridique ${ }^{3}$. Néanmoins, le phénomène commence à retenir l'attention depuis qu'une percée biotechnologique récente provoqua, tant de la part des citoyens que des professionnels de la police et de la justice, un immense débat. Il s'agit de la preuve d'identification par ADN.

En effet, cette preuve biométrique, mise au point en 1985 par un généticien britannique, Alec Jeffreys, fascine. C'est presqu'un truisme de dire qu'elle est séduisante et particulièrement prometteuse, non pas seulement parce qu'elle repose sur une biotechnologie de pointe, la génétique, mais surtout parce qu'elle permet, soit de désigner avec une quasi-certitude, de confirmer une identité sans un besoin de témoignage ${ }^{4}$, soit d'exclure une telle identité. Les résultats d'un test d'identification par ADN sont plus significatifs, plus

1. Conception utilitariste de la répression pénale que l'on retrouve chez Caesare BECCARIA, Traité des délits et des peines, Flammarion, Champs, 1979.

2. La loi en distingue particulièrement deux sortes : les preuves directes qui établissent la conviction du juge par la simple constatation des faits, et les preuves indirectes qui entraînent la conviction à la fois par l'observation et le raisonnement.

3. Voir N. LAURENDI, «Opposition to the Admissibility of Lie Detector Test in Criminal Cases», dans E.J. IMWINKELRIED, ed., Scientific and Expert Evidence, 2ème éd., New York, Practising Law Institute, 1981, 805, p. 813. Il faut mentionner ici qu'il existe une grande polémique quant au caractère scientifique du polygraphe; la valeur scientifique et la fiabilité de cette technique ne sont pas reconnues de façon générale; voir à ce sujet Céline LACERTE-MONTAGNE, le polygraphe en droit canadien, Mémoire de Maîtrise, Université de Montréal, 1983, pp. 35-46.

4. La preuve d'identification par ADN individualise en identifiant un ou plusieurs coupables. 
informatifs que ceux des techniques biologiques traditionnelles. Dès lors, leurs utilisations se multiplient devant les tribunaux civils et criminels ${ }^{5}$. L'intérêt considérable que suscite cette technique est universel. L'OTA (Office of Technology Assessment) a recensé, en 1990, 15 pays qui ont déjà implanté cette technique chez eux ${ }^{6}$; depuis, quelques autres États se sont joints au groupe ${ }^{7}$. La Grande-Bretagne l'utilise annuellement dans plus de 3000 cas $^{8}$ pour contrôler la véridicité de la parenté en matière d'immigration et y détecter les fraudes. Le domaine des expertises médico-légales n'y échappe pas non plus. En France, la pratique concerne principalement les domaines du droit de la famille ${ }^{9}$ et du pénal; cependant tout récemment ce pays s'est découvert une autre perspective: l'identification des cadavres morcelés des victimes de l'écrasement de l'airbus A $-320^{10}$. La police espagnole l'utilise en matière criminelle dans deux instituts médico-légaux ${ }^{11}$. Curieusement en Belgique, où le phénomène biotechnologique a pris naissance en 1986, un «circuit clandestin» ${ }^{12}$ de preuves scientifiques se développe dans le domaine de la paternité. Aux États-Unis, on note une poussée fulgurante dans les procédures de paternité et dans les investigations criminelles: on dénombre 2000 investigations à la fin de 1990. De plus, la méthode a été

5. Voir James WATSON, M. GILMAN et al, Recombinant DNA, W. H. Freeman and Company, New York, 2ème édition, 1992, p. 563.

6. OTA, (OFFICE OF TECHNOLOGY ASSESSMENT), Genetic Witness : Forensic Uses of Data Tests, Washington, 1990. Ces pays sont : l'Australie, la Finlande, le Danemark, l'Espagne, l'Inde, l'Irlande, le Canada, La Pologne, La France, La Grande-Bretagne, La Suisse, la Suède, l'Allemagne, l'Italie, Israël.

7. Par exemple, le Japon, le Costa Rica; ce dernier a envoyé des biologistes se familiariser aux États-Unis avec cette méthode (Voir Ronald MOYA CHACON «La Genetica Lucha contra el Crimen» La Naccion Costa Rica, 27 janvier 1992, p. 10.

8. James WATSON, M. Gilman et al., op. cit., note 5, p. 563.

9. Les empreintes génétiques servent à clarifier les relations familiales en cas de contestation (en matière de filiation naturelle) ou de doute (consanguinité qui constitue un empêchement au mariage selon les articles 161 à 163 du code civil français) : voir Jean-Christophe GALLOUX, «L'empreinte génétique : la preuve parfaite», (1991) JCP, 1, 3497,106-107; Voir aussi N. LENOIR, Aux frontières de la vie : paroles d'éthique, Paris, La documentation Française, 1991, p. 71 pour un exemple d'échange ou de mélange de nouveaux-nés dans un hôpital.

10. Jean-Yves NAU, «Les victimes de la catastrophe du mont Sainte-Odile ont été identifiées grâce aux empreintes génétiques», Le Monde, 31 mars 1992, p. 32.

11. N. LENOIR, op. cit., note 9, p. 424.

12. Christiane HENNAU-HUBLET, «Les demandes officieuses de comparaison d'empreintes génétiques et le droit de la filiation», (1991) 72 Athéna, pp. 35-36. 
admise dans 45 États $^{13}$. Au Canada, ses domaines d'application sont actuellement la filiation, le domaine des infractions criminelles et le secteur de l'immigration $^{14}$. Quatre laboratoires publics ${ }^{15}$ et une entreprise privée ${ }^{16}$ se partagent pour l'instant le marché.

Quoique l'usage de cette méthode d'investigation soit encore restreint, il ne fait aucun doute qu'elle sera utilisée de plus en plus par les autorités policières soucieuses d'arrêter le plus rapidement les suspects afin de les traduire devant les tribunaux criminels.

En matière criminelle, cette preuve est particulièrement utile dans les causes de meurtres, de viols ou d'agressions sexuelles, de vols qualifiés, de crimes en série et de crimes non résolus où il n'est pas facile de trouver des preuves sur la base des méthodes traditionnelles. De toute évidence, la fonction utilitaire est la même que celle de la méthode traditionnelle des empreintes digitales; au Canada, cette dernière est déjà régie par la Loi sur l'identification des criminels. En effet, les empreintes digitales et les empreintes génétiques partagent plusieurs caractéristiques communes : même nature de preuve, même procédure technique, mêmes problèmes d'interprétation, mêmes craintes pour le respect des droits fondamentaux etc...

L'administration judiciaire canadienne se trouve donc confrontée à l'admissibilité de la preuve d'identification génétique sur laquelle elle doit trancher, ce avant même qu'aucune norme ne soit votée sur les exigences de contrôle de cette technique, son champ d'application, les mesures de cueillette et de conservation des échantillons et la mise en banque des informations recueillies.

13. OTA, op. cit., note 6, p. 14.

14. Le laboratoire Hélix Biotech, en Colombie Britannique, qui détient le brevet de Lifecodes, offre ces tests pour $975 \$$ par cas et les résultats sont acceptés par le ministère de l'Immigration du Canada en vertu de la politique IS 1.26 et de l'amendement IS 45.

15. Ce sont : le laboratoire central d'analyse judiciaire de la GRC à Ottawa, le Center of Forensic Science à Toronto, la direction des expertises judiciaires à Montréal, une filiale de la GRC à Edmonton et une autre à Halifax.

16. Il s'agit du laboratoire Hélix Biotech : supra, note 14. Celui-ci vient d'ouvrir tout récemment un bureau de représentation à Montréal. 
Pourquoi donc cet engouement social et mondial pour cet outil biotechnologique? Pourquoi abandonner les systèmes traditionnels d'identification pour cette technique hautement complexe? Quels avantages apporte-t-elle ou apportera-t-elle à nos tribunaux canadiens? Constitue-t-elle une meilleure solution à nos problèmes d'identification ${ }^{17}$ ? Rencontrera-t-elle des objections à son admissibilité dans notre droit de la preuve et quel poids doit-on lui accorder en matière criminelle?

Comment concilier le progrès biotechnologique et les valeurs fondamentales de la société canadienne? Quelle sorte d'instrument juridique devrait émerger à l'égard de ce progrès technologique?

Autant d'interrogations auxquelles il nous faut répondre en déterminant «le pourquoi et le comment» d'une admission des résultats de cette technique qui, peut-être, «révolutionnera» le système pénal, dans notre système accusatoire. La question est d'actualité et aussi pressante, vu le nombre de cas qui affluent devant nos tribunaux tant au Québec qu'au Canada. On ne peut ignorer non plus l'aspect médiatique sensationnel de cette méthode traduit par les titres suivants : «L'empreinte de vos doigts est plus facile à cacher que votre empreinte génétique» ${ }^{18}$; «Sida, les empreintes génétiques permettraient d'identifier à coup sûr qui contamine qui» ${ }^{19}$; les empreintes génétiques «reine des preuves ${ }^{20}$. Ainsi, les médias de masse ont mis l'accent sur l'aspect le plus spectaculaire de la preuve d'identification, créant de ce fait des imaginaires sociaux $^{21}$.

17. L'identification par témoin oculaire et le défilé d'identification sont les types de preuve les plus susceptibles d'entraîner une erreur judiciaire, à cause de leur fiabilité minime.

18. La Presse, 30 août 1992, p. B 6.

19. Le Devoir, 23 juillet 1992, p. 3.

20. Gilbert CHARLES, «Génétique : tous en fiches», (1992) Express, 20 mars, p. 46.

21. Les médias d'information, en présentant un discours-spectacle de la preuve d'identification par ADN, amènent le public profane à se construire des représentations bien différentes de la réalité; ainsi la preuve d'identification est imaginée comme un outil tout puissant capable de contrôler totalement et efficacement la criminalité. Or, imaginaires sociaux et représentations sociales ne se conçoivent pas «indépendamment les uns des autres» mais évoluent «plutôt sous un même toit dans un rapport symbiotique». Voir Caroline MEUNIER, les représentations sociales et les imaginaires sociaux de la nouvelle génétique tels que perçus à travers les différents niveaux de la vulgarisation écrite, Mémoire de Maîtrise, Université de Montréal, 1993, pp.143 et ss. 
Quoiqu'il en soit, le débat juridique et éthique est lancé à travers le monde avec, en toile de fond, un cadre bien défini à ce moyen de preuve. Des instances juridiques, législatives et éthiques de plusieurs pays ont donc commencé à réagir sous forme de recommandations, de rapports ou de règles juridiques. De ce fait, il nous semble que le droit pénal canadien ne doit pas rester en «poste d'observation». Il lui faut adopter une perspective réaliste à l'égard de cette preuve qui est susceptible d'être largement utilisée dans l'avenir.

Pour les besoins de notre analyse, nous allons d'abord présenter une esquisse de l'aspect technique de la méthode d'ADN puisque sa force probante devant les tribunaux en dépend (I). Par la suite, nous aborderons le cadre conceptuel de cette méthode, c'est-à-dire les principes qui devraient sous-tendre la recevabilité au Canada d'une telle preuve (II). Enfin, nous discuterons des pratiques normatives qui devraient encadrer l'utilisation de cette nouvelle preuve dans la perspective d'un équilibre entre l'intérêt public et le droit des citoyens (III).

\section{I- APERÇU TECHNIQUE DE LA MÉTHODE}

La méthode qui permet d'identifier une personne par examen génétique est assise sur un axiome scientifique cartésien : l'unicité génétique. Le substrat en est l'ADN (A). Ici, on n'agit pas sur le gène, on rend seulement visible l'information en se concentrant sur les fragments de la molécule d'ADN qui diffère d'un individu à un autre. Pour parvenir à cette fin, différentes techniques existent sur le marché (B).

\section{A- Le substrat : l'ADN}

La découverte de l'ADN en 1940 et de sa structure en 1953 a permis de comprendre le mystère de l'hérédité. L'ADN est une molécule très importante présente dans les cellules vivantes puisqu'elle constitue le support matériel de l'information génétique. L'ADN se trouve principalement dans toute cellule nucléée; par voie de conséquence les globules rouges, cellules anucléées contenant de l'hémoglobine, ne possèdent pas d'ADN. L'ADN ainsi analysé est appelé l'ADN nucléaire. Cependant, il arrive qu'on retrouve aussi de l'ADN dans d'autres structures extra-nucléaires (à l'extérieur du noyau), notamment dans les mitochondries, structures qui se trouvent dans le cytoplasme et qui sont 
essentiellement une source énergétique. Cet ADN mitochondrial est, selon certains auteurs, plus facile à détecter que l'ADN nucléaire ${ }^{22}$. Il faut cependant noter cette particularité de l'ADN mitochondrial à savoir qu'il ne se transmet que par les femmes et est plus sensible à des mutations ${ }^{23}$.

Structurellement, l'ADN a la forme d'une spirale à double hélice formée de deux brins complémentaires qui sont orientés dans des directions opposées mais qui sont reliés entre eux par des liaisons d'hydrogène. Chaque brin est composé de 4 nucléotides ou bases symbolisées par leur première lettre : guanine (G), adénine (A), thymine (T) et cytosine (C). Celles-ci s'apparient deux à deux et uniquement selon une séquence bien définie : $\mathrm{A}$ avec $\mathrm{T}$ et $\mathrm{G}$ avec $\mathrm{C}$ et vice-versa. Ces paires de bases sont au nombre de 3,3 milliards, entrent dans la composition des 50000 à 100000 gènes qui composent le génome humain et sont réparties sur nos 23 paires de chromosomes. Des trois milliards de paires de bases composant la cartographie humaine, seulement trois millions diffèrent entre deux individus, soit 10\%. L'ADN contient des régions codantes (exons) et des régions non codantes ${ }^{24}$ (introns). Contrairement aux séquences codantes, les non codantes montrent uniquement l'organisation génétique propre à chaque individu et ne révèlent aucune maladie héréditaire ni aucune prédisposition. Ces séquences non codantes présentent des variations d'un individu à un autre et sont utiles pour la technique d'identification à l'ADN. En principe la composition de l'ADN d'un individu ne varie pas d'une cellule à une autre, qu'elle provienne du sang, de la salive ou des cheveux, car l'ADN est une molécule de l'hérédité. ${ }^{25}$ On compare cette molécule à «une bibliothèque biochimique fermée à l'intérieur de chaque cellule, et qui détermine les caractéristiques de chaque personne» ${ }^{26}$. L'ADN confère donc à chaque être humain son individualité. On parle d'unicité

22. Agence France-Presse, «Est-ce la fin du mystère de la famille Romanov?» La Presse, 10 juillet 1993, p. A 20.

23. Le taux de mutation est de 10 fois supérieur à celui de l'ADN nucléaire.

24. La fonction de ces régions non codantes est encore largement inconnue.

25. Grâce aux travaux du moine autrichien Gregor Mendel on a pu établir que les unités de l'hérédité ou gènes sont localisés sur les vingt-trois paires de chromosomes (vingt-deux paires de chromosomes autosomales, identiques chez les hommes et les femmes, et une paire de chromosomes sexuels). Ces gènes proviennent pour moitié du père et pour moitié de la mère et sont transmis fidèlement sauf en cas de mutations. Les gènes étant composés chimiquement d'ADN, on peut donc déduire que l'ADN est la clé du pouvoir de l'hérédité.

26. Mark J. FUHRMAN, DNA Fingerprinting Admissible under Frye. Mémoire de MA, University of Nevada, Reno, 1989, p. 1. 
génétique pour chaque individu, exception faite des jumeaux homozygotes ou identiques ${ }^{27}$.

L'ADN en tant que matériel génétique possède les propriétés suivantes : il stocke l'information biologique, la transmet avec le minimum d'erreur à la cellule en fonction des besoins de celle-ci, réplique fidèlement cette information pendant la croissance de l'individu et la transmet de génération en génération. Ces propriétés expliquent la disponibilité et la similitude de l'information quel que soit l'élément biologique utilisé chez un même individu. Elles sont aussi à la base de l'efficacité des tests d'identification qui mettent en évidence le polymorphisme.

L'identification génétique en matière criminelle se divise en deux étapes : procéder d'abord à la typologie des divers échantillons (ceux relevés sur le lieu du crime et ceux du ou des suspects), ensuite comparer ces typologies. Ces deux procédés ne sont pas nouveaux ${ }^{28}$; en conséquence nous n'entreprendrons pas une étude de ces phases. Nous nous attacherons plutôt aux grandes procédures d'analyse qui permettent de lire le code génétique de l'individu.

\section{B- Les techniques d'identification génétique}

La génétique facilite l'accès à l'identité par le biais de techniques dont les principales sont : la méthode Southern encore appelée technique du polymorphisme de restriction ou Restriction Fragment Length Polymorphism (RFLP) et celle de l'amplification désignée communément sous le vocable de PCR (Polymerase Chain Reaction) (1). On devine aisément l'impact d'une telle révélation à partir d'éléments biologiques infimes. D'où l'importance de la fiabilité et d'un contrôle rigoureux des techniques (2).

27. Conal MULLEN, «DNA Tests Proved Twin Sisters Are Identical» (1992) Edmonton Journal, August 23, p. 11.

28. Ces procédés sont déjà utilisés depuis plusieurs années par les services de l'identité judiciaire. 


\section{1- Les méthodes d'analyse proprement dites}

\subsection{La méthode de Southern}

C'est pour l'instant l'outil le plus largement utilisé pour analyser les échantillons biologiques dans le domaine des sciences criminelles ${ }^{29}$. L'analyse du polymorphisme de restriction par la méthode de Southern permet de percevoir les différences de taille des fragments d'ADN à des endroits spécifiques du code génétique. Cette méthode connue sous l'abréviation de RFLP utilise un couple de sonde et d'enzyme de restriction pour montrer la variabilité des minisatellites entre les individus. Elle comprend plusieurs étapes : l'extraction de l'ADN à partir de l'échantillon, la digestion de l'ADN en fragments par les enzymes de restriction, la séparation des fragments d'ADN par électrophorèse, la séparation des deux brins de molécules qui seront fixés sur une membrane en nylon, l'hybridation de la région suspectée avec une sonde marqueur, la visualisation de l'image obtenue sur autoradiogramme et l'interprétation des résultats. Deux sortes de sondes sont utilisées par les laboratoires :

--- Les sondes multilocus mises au point par Jeffreys. Celles-ci sont capables de détecter de nombreux fragments d'ADN simultanément chez un individu et la fréquence de bandes communes entre des individus, d'où la qualification d'empreintes génétiques. Ces sondes exigent une grande quantité d'échantillons biologiques contenant une proportion importante d'ADN. La probabilité d'identification dépend du nombre de bandes détectées sur les autoradiographies. Ce type d'analyse est plus fiable dans les recherches de paternité.

Les sondes monolocus, quant à elles, sont plus adaptées pour l'identification en criminalistique. Ici les minisatellites sont visualisés sur un seul site à la fois. Moins discriminatives que les sondes multilocus, elles montrent en échange des images parfaitement nettes.

29. La nouvelle technique de $P C R$ modifiera probablement ce schéma à cause des nombreux avantages qui y sont reliés. Déjà cette technique est mise en place dans de nombreux laboratoires dans le but d'optimiser leur rendement. Pour plus de détails sur les avantages de cette technique, voir 1.2. la méthode d'amplification ou PCR. 
Le calcul de probabilité est basé sur des études de populations permettant d'apprécier la fréquence des allèles sur un locus donné. La probabilité sera donc d'autant plus petite que les allèles observés sont rares.

Que ce soit avec les sondes multilocus ou monolocus la durée de l'identification par la méthode du polymorphisme de restriction est considérable : 3 semaines environ pour un multilocus et 8 à 10 semaines avec une sonde monolocus; la quantité de matériel à manipuler est substantielle et la qualité de l'ADN doit être remarquable. Cette technique ne peut donc être utilisée pour tous les types d'échantillons. En effet, sur les lieux du crime on retrouve parfois très peu d'échantillons biologiques ou du matériel contenant une quantité minime d'ADN ${ }^{30}$. La $P C R$ vient donc contrer ces limites matérielles et permet de procéder à l'identification.

\subsection{La méthode d'amplification ou $P C R$}

Elle marque un bond technologique dans le domaine de la génétique. Pour beaucoup de scientifiques, c'est la technique qui permettra de dresser la carte génétique. Elle permet la synthèse de milliers de copies d'une séquence spécifique (inférieure ou égale à $2 \mathrm{~kb}$ ) d'ADN à l'aide d'une enzyme, la Taq polymérase. C'est un procédé de choix qu'on emploie dans les investigations criminelles lorsque les éléments matériels trouvés sont de quantité très infime rendant ainsi impossible l'analyse par la méthode de RFLP. On peut aussi traiter en même temps un très grand nombre d'échantillons. Ici la technique de l'analyse est de déterminer la constitution allélique des échantillons. La PCR est un outil de typage qui permet de court-circuiter certaines étapes de l'analyse ${ }^{31}$, car elle est fondamentalement basée sur des variations thermiques rendant possible la réalisation de tous les cycles dans un même tube. L'amplification exponentielle n'exige pas de l'ADN hautement purifié ni un haut rendement d'ADN pour

30. L'ADN peut être dégradé par les éléments naturels (la lumière, l'humidité, la moisissure etc...); les cellules peuvent être détruites par des bactéries ou des virus; ces limites ne sont pas associées spécifiquement aux échantillons trouvés sur les lieux du crime, puisque chez les malades du sida, il peut avoir aussi un faible pourcentage (1 sur 100 000) de globules rouges contenant des séquences d 'ADN.

31. L'étape du clonage est ici inutile. 
pouvoir donner un signal détectable pour l'identification. L'identification est obtenue très rapidement (trois jours au plus), ce qui est pratique. De même, les résultats se présentent sous forme de code digital pouvant être stockés directement sur ordinateur. Cette méthode tend à remplacer la méthode de Southern même si elle a des faiblesses techniques inhérentes ${ }^{32}$ à son extraordinaire capacité d'amplification. ${ }^{33}$

Actuellement, Jeffreys cherche à élargir les possibilités d'identification, d'une part, en perfectionnant une technique fondée sur la différence de taille des séquences, et d'autre part, en travaillant sur l'ADN génomique total; de ce fait, il y aura un gain de temps appréciable. Cette dernière trouvaille du généticien, appelée $M V R-P C R^{34}$, fournit des données objectives et permet d'établir des banques de données plus étendues. On lui reconnaît de nombreux avantages entre autres : sensibilité, richesse d'information, stockage et manipulation facile des résultats. Cette méthode est basée sur le fait que chaque minisatellite est composé d'éléments répétitifs différents qui se suivent dans une séquence donnée. Il faut donc montrer cette diversité inter-individuelle. Le «Digital DNA Typing» requiert que l'on travaille sur des séquences courtes; ainsi l'ADN dégradé et de très petite quantité peut être utilisé et donner des résultats significatifs; le succès de la technique repose sur l'informatisation puisque les calculs de probabilité sont faits directement par ordinateur. Pour attirante qu'elle soit, cette méthode n'est pas encore opérationnelle et, de toute façon, il faut auparavant juger de sa portée et de sa fiabilité comme il en est des techniques précédemment citées.

\section{2- La fiabilité des méthodes d'identification génétique}

Comme pour toute technique scientifique, la fiabilité des différentes méthodes (la méthode de Southern et celle de l'amplification) est jaugée en vertu de leurs avantages et de leurs faiblesses.

32. La contamination, entre autres, est un problème bien réel mais qui peut être détecté par des contrôles négatifs de laboratoire.

33. La $P C R$ peut générer des milliards de copies d'ADN à partir seulement d'une séquence.

34. Jean-Claude DREYFUS, «Le typage de l'ADN : vers l'automatisation des empreintes génétiques», (1992) 8 Médecine/Sciences, pp. 8-9. 


\subsection{Les nombreux avantages liés au caractère intrinsèque du matériel utilisé}

Six grands types d'avantages peuvent être répertoriés. Ce sont :

\subsubsection{La facilité dans la cueillette des éléments de preuve à cause de :}

la variété des échantillons : contrairement aux tests traditionnels, la méthode de l'identification génétique ne se limite pas à l'analyse d'un seul type de liquide ou de tissus mais compare une molécule commune située dans les cellules de l'organisme. Les matériaux biologiques peuvent donc être de nature diverse (salive, sang, sperme, sécrétions vaginales, urine, peau, rognures d'ongles, pulpe de dent, cheveu, liquide amniotique etc...). De ce fait, il semble plus facile de recueillir des échantillons biologiques que de relever des empreintes digitales ${ }^{35}$.

la nature des échantillons : la source de l'échantillon utilisé pour l'analyse peut être variable (prélèvements frais, vieux, secs, congelés, décomposés) car l'ADN est stable et est extrêmement résistant aux effets de l'environnement. Par exemple, on est arrivé à isoler l'ADN de momies égyptiennes vieilles de plusieurs milliers d'années ${ }^{36}$.

la petitesse des échantillons : la quantité d'échantillon nécessaire pour l'analyse est minime : quelques racines de cheveux ${ }^{37}$, une quantité

35. Les criminels font attention à ne pas laisser d'empreintes digitales sur les lieux du crime ou s'évertuent à les embrouiller; mais c'est compter sans les traces biologiques. Ainsi sur de la gomme mâchée, on peut trouver de l'ADN; de même on peut en extraire sur un mégot de cigarette : voir Mike KING, «Cigarette Butts Led to Man's Conviction for Killing Neighbor», (The Montreal) Gazette, June 4, 1994, p. A-3.

36. James WATSON, M. GILMAN et al., op. cit., note 5, p. 86.

37. Avec la $P C R$, on peut aller jusqu'à une seule racine. 
minimale de sang ${ }^{38}$, un ongle, 1.5 millilitre d'urine etc. On peut même «envisager une analyse de l'ADN à partir d'une seule cellule» ${ }^{39}$.

\subsubsection{La simplicité de visualisation}

La technique d'identification par $\mathrm{ADN}$ produit un film rayon $\mathrm{X}$ encore appelé autoradiogramme et qui est facile à observer visuellement. En effet, après exposition de la membrane en nylon au rayon $\mathrm{X}$, les sondes radioactives attachées à l'ADN produisent une image qui correspond à leur position sur la membrane en nylon. Ces images se présentent sous forme de taches ou de bandes similaires en apparence aux codes universels visibles sur les emballages de produits. L'étape suivante consiste à examiner à vue d'oeil l'autoradiogramme et à comparer ces bandes pour voir s'il y a superposition entre les bandes de l'échantillon connu et celles de l'échantillon étudié.

\subsubsection{La certitude d'appariement basée sur la concordance des échantillons}

Un consensus scientifique s'est établi quant à la détermination de l'appariement de deux échantillons. Les fragments d'ADN étant de grosseur différente, on évalue d'abord la longueur des fragments des échantillons inconnus en les comparant, à l'aide d'un ordinateur, aux fragments d'échantillons connus. On se sert donc des chiffres obtenus pour affirmer s'il y a appariement ou non. Les laboratoires appliquent une pondération qui peut aller jusqu'à plus ou moins $2,5 \%{ }^{40}$ pour leur calcul, car en réalité les mesures identiques ne sont pas toujours observées. Ainsi, lorsqu'il y a concordance positive des échantillons, on conclut qu'elles proviennent de la même personne et qu'il y a appariement.

38. 0.5 microlitre de sang est suffisant pour la technique de PCR, on parle même «d'une tête d'épingle, alors que pour un test sanguin traditionnel un minimum de $10 \mathrm{ml}$ est requis; ainsi seuls les enfants de plus d'un an peuvent être soumis à un tel prélèvement.

39. Jean-Claude DREYFUS, « les empreintes génétiques : la révolution permanente», (1990) 6 Médecine /Sciences, p. 690.

40. Valeur expérimentale qui provient du FBI; mais la GRC applique seulement une pondération de plus ou moins 2,6\%. Quant à la direction des expertises judiciaires à Montréal, son taux est de plus ou moins 2,5\%; ce qui fait une fenêtre totale de concordance, c'est-à-dire une différence maximale admissible, d'environ $5,1 \%$. 


\subsubsection{La force de probabilité de précision et d'individualisation}

Le calcul de la fréquence des gènes est une étape indispensable. Quand on connaît la fréquence des gènes dans une population donnée, on peut estimer la fréquence du profil étudié. Dans le cas de la preuve d'identification par ADN, la probabilité de fréquence d'un même profil génétique, c'est-à-dire le risque que deux individus aient le même profil génétique, est très bas ${ }^{41}$; on l'estime, selon les cas, à un sur plusieurs dizaines de millions voire des dizaines de milliards. La méthode d'identification par ADN a donc une précision redoutable qu'on ne rencontre ni avec les empreintes digitales, ni avec les groupes sanguins.

\subsubsection{La discrimination évidente}

La technique d'identification par ADN permet de distinguer l'ADN de différentes sources. Ainsi dans le cas de mélange des éléments biologiques, la distinction entre différents codes génétiques est nettement visible en examinant les autoradiogrammes des échantillons même si les substances ou les échantillons étaient enchevêtrés. Par exemple dans le cas des agressions sexuelles, où on se trouve en présence de mélange de cellules vaginales de la victime et du sperme du suspect, une technique différentielle permet d'isoler l'ADN de chaque substance ${ }^{42}$. On arrive au même résultat dans une hypothèse de plusieurs violeurs, de sang amalgamé trouvé sur les lieux du crime, de mélange de sang avec d'autres organismes, ce qui rend moins fiable toute autre méthode d'analyse.

\subsubsection{La rapidité des analyses}

D'un délai de quelques semaines pour obtenir un profil génétique avec le procédé de polymorphisme de restriction $(R F L P)$ qui détecte les différences de taille des fragments d'ADN à des loci (adresses spécifiques), on passe à un délai de trois jours avec le procédé de l'amplification $(P C R)$ qui multiplie la

41. Excepté les jumeaux homozygotes.

42. Notons que même s'il n'y a pas eu éjaculation du suspect, on peut procéder à l'analyse s'il y a seulement quelques traces de cellules. Voir Ulf B. GYLLENSTEN et Al., «DNA Typing of Forensic Material with Mixed Genotypes Using Allele-Specific Enzymatic Amplification», (1992) 52 Forensic Science International, pp. 149-160. 
molécule d'ADN jusqu'à obtention d'un nombre de copies suffisantes pour des analyses subséquentes. ${ }^{43}$ On peut donc, par ce procédé, traiter plusieurs cas dans le même laps de temps, ce qui réduit considérablement les délais.

Ces atouts liés aux analyses génétiques dépendent toutefois du rigorisme qui y est appliqué, car comme toute technologie, la méthode des analyses génétiques est sujette à des imperfections et possède des limites qui lui sont intrinsèques.

\subsection{Les problèmes potentiels}

Les problèmes susceptibles de se présenter concernent l'aspect technique et l'interprétation des résultats.

\subsubsection{Les questions techniques}

---- la dégradation de l'ADN peut provoquer pendant l'analyse des déplacements de bandes.

---- la résolution peut être influencée par des variations de la densité du gel, le voltage électrique, ainsi que par la grosseur des fragments observés lorsque ceux-ci se chevauchent.

---- dans l'hypothèse d'une transplantation et d'une transfusion, un problème peut naître : en effet, il est de connaissance générale que les lymphocytes ne sont pas «neutres» et peuvent modifier le génotype des transfusés et des transplantés. Ainsi, pour un individu ayant eu une transplantation d'organe réussie, les génotypes provenant de l'organe transplanté et de son sang, par exemple, peuvent parfois être différents. Il est intéressant de noter que ce problème peut aussi se révéler dans le cas d'une transfusion sanguine lorsque la préparation transfusée contient des globules blancs. Il faut bien souligner qu'il s'agit d'éventualités rarissimes.

43. Pour ces procédés, voir OTA, op. cit., note 6, pp. 42-48. 
les mutations : en principe, un enfant reçoit la moitié de ses gènes de sa mère et l'autre moitié de son père, ce qui fait qu'il présente à chaque génération des caractères propres à ses parents; c'est l'aspect essentiel de l'hérédité. Cependant, il peut arriver que des mutations d'un allèle, donc du génome, surviennent dans une génération, entraînant ainsi une nouvelle taille du fragment. Les chercheurs évaluent la probabilité de mutation à cinq pour cent ${ }^{44}$.

Outre ces problèmes techniques, des erreurs peuvent aussi résulter lors de la phase de l'interprétation des résultats d'appariement par l'expert.

\subsubsection{Les questions d'expertise et d'interprétation}

L'expertise s'effectue au niveau de la génétique de la population pour les statistiques, et au niveau de la probabilité de la fréquence des allèles qui soustendent le calcul de la probabilité de l'identité.

\section{---- Aspects controversés de l'interprétation}

La subjectivité de l'interprétation est un facteur essentiel important de l'ambiguité, car ici tout est fonction de la compétence de l'expert, de son expérience, de son sens d'observation et de sa vigilance. C'est un véritable danger de faire une interprétation sur des bandes manquantes, des extra-bandes des autoradiogrammes. De plus, un taux de variation très grand entre la grosseur du fragment de l'échantillon connu et celui qui est inconnu peut fausser le sens du résultat. 5\% semble bien être la limite et il faut arriver à diminuer cette limite ou l'annuler. De même, la probabilité doit se définir en fonction de la rareté des allèles, du profil. On regarde donc la fréquence de ceux-ci dans une population donnée, ce qui nécessite l'utilisation de bonnes statistiques.

44. Dan BURK, «DNA Identification : Possibilities and Pitfalls revisited», (1990) 31(1)

Jurimetrics, p. 60. 


\section{---- L'expert et la population de référence}

Une fois la concordance établie entre deux échantillons, il reste à déterminer les chances de retrouver ce profil génétique dans la population. Cette tâche revient donc à l'expert en génétique de population. Celui-ci détermine la fréquence d'un allèle spécifique à l'intérieur d'un sous-groupe donné et pour cela il consulte une banque de données. Devant les tribunaux, les études de population ont soulevé de nombreuses interrogations et il y eut beaucoup d'objections au sujet de la base de la démogénétique. Est-ce qu'il y a une population de référence appropriée et est-il pertinent d'en tenir compte au moment du calcul de probabilité? De même, peut-on avoir une certitude à propos de la provenance raciale des statistiques utilisées ${ }^{45}$ ?

La question de référence à une population appropriée pour les calculs de probabilité demeure un problème clé. En effet, les banques de données sont constituées par races ou par groupes (caucasiens, noirs, asiatiques etc...) et les spécialistes en génétique de population ne considèrent pas le fait qu'à l'intérieur des groupes ou des ethnies il y a des sous-groupes ayant des traits génétiques spécifiques (par exemple, les noirs américains sont différents génétiquement des noirs qui sont restés en Afrique, les chinois nés en Amérique du Nord présentent des traits génétiques différents de ceux qui sont en Chine etc...). Les sousgroupes ne sont pas homogènes, c'est-à-dire qu'on retrouve plus souvent certains fragments d'ADN dans un sous-groupe que dans l'autre même si ensemble les deux font partie de la même population ethnique ${ }^{46}$. Selon McElfresh et al., la

45. Les échantillons de sang utilisés pour la constitution des banques de données génétiques proviennent des organismes tels la Croix Rouge. Ces échantillons ne sont pas identifiés spécifiquement et ne contiennent aucun renseignement personnel. On fait confiance à l'organisme pourvoyeur pour la classification par sous-groupes (la race etc...). Nonobstant le rigorisme des laboratoires, il peut arriver que des échantillons de plusieurs sous-groupes se mêlent. L'emploi d'une population génétique de référence adéquate est donc important pour déterminer la fréquence de l'allèle.

46. Voir Brad DAISLEY, « Uses of Databases Has Sparked Controversy Over DNA Typing», (1993) 40 The Lawyers Weekly, p. 17. Voir aussi Kenneth R. KREILING, «Review Comment : DNA Technology in Forensic Science», (1993) 33 Jurimetrics, pp. 476-480; Kevin C. McELFRESH, Debbie VINING-FORDE, and Ivan BALAZAS, «DNA-Based Identity Testing in Forensic Science», (1993) 43(3) BioScience, p. 149; Peter ALDHOUS, «Congress Reviews DNA Testing», (1991) 351 Nature, p. 684; Douglas M. SMITH, « Genetic Witness : By thy DNA So Shall Ye Be Known», (1993) 1 Health Law Journal, p. 
structure démographique n'implique pas une diversité génétique entre les populations ${ }^{47}$. À ces questions de population de référence, il faut ajouter celles de calculs statistiques. Par ailleurs, la qualité et l'expérience de l'expert sont très importantes. Son expertise en génétique de la population doit être démontrée.

Ces difficultés évoquées ne nous amènent cependant pas à tirer des conclusions défavorables à l'encontre de la méthode d'identification génétique car, comme nous l'avons souligné, celle-ci a un haut potentiel de discrimination; elle est porteuse d'espoir en matière criminelle, puisqu'elle permet de déterminer si les échantillons biologiques provenant des scènes de crime appartiennent à la personne suspectée, à un seul individu ou à plusieurs. C'est une technique d'identification positive. C'est un instrument pour résoudre l'énigme de l'identité, pour prouver la culpabilité ou l'innocence d'un individu ${ }^{48}$, pour «mettre l'accusé en première place $»^{49}$. Elle sert aussi bien au niveau de l'enquête policière que dans toutes les phases de la procédure judiciaire.

En règle générale, la qualité des résultats des analyses génétiques fait l'objet de peu de questionnement de la part des scientifiques et de la police, cependant on remarque que la preuve ainsi obtenue est encore scrutée devant la justice. En effet, la preuve d'identification par ADN, à cause de sa récente apparition, fait partie de cette catégorie de preuves scientifiques qui, au Canada, n'ont pas encore obtenu le consensus de critères d'admissibilité; aussi en l'absence de standards il importe de nous interroger sur les critères adéquats de sa recevabilité comme preuve devant nos tribunaux.

207.

47. Kevin C. MCELFRESH, Debbie VINING-FORDE, and Ivan BALAZAS, loc. cit., note 46.

48. D. C. MOSS, «Free at Last», (1989) 75 A.B.A. Journal, p. 19 : Garry Dotson, accusé en 1979 à tort d'un viol qu'il n'a pas commis, s'est vu refuser sa libération bien que la victime 5 ans plus tard ait reconnu son erreur. Mais en 1988, il fut déclaré innocent après avoir accepté de se soumettre au test des empreintes génétiques.

49. I. LOMHOFF, «By Their DNA, So Shall Ye Know Them », (1987) California Lawyer, p. 9. 


\section{II- LA RECEVABILITÉ DE LA PREUVE D'IDENTIFICATION PAR ADN EN DROIT PÉNAL CANADIEN}

Dans le système pénal canadien, comme d'ailleurs dans beaucoup de systèmes étrangers, la présomption d'innocence est une règle fondamentale; ainsi, nul ne peut être déclaré coupable sans un procès juste et équitable ${ }^{50}$. L'admissibilité de toute preuve scientifique est décidée au cours d'un voir-dire où le juge évalue avec prudence la légalité de la preuve obtenue, sa fiabilité et sa pertinence puisque la présentation des résultats aura une importance capitale sur la culpabilité ou non de l'accusé. La common law et différents textes de lois ont érigé de grands principes d'admissibilité de la preuve en tenant compte de la diversité des modes de preuve; cependant, ces règles ne pourront recevoir application que si elles sont compatibles avec la Charte canadienne des droits et libertés ${ }^{51}$.

En tant que technique scientifique nouvelle, les analyses génétiques ne sont pas encore réglementées par le droit de la preuve au Canada. Il faut, dans ces conditions, se demander comment les tribunaux admettent cette méthode en l'absence de lignes directrices spécifiques? (A) Y-a-t-il une remise en question de la théorie contemporaine de la recevabilité de la preuve au Canada? En d'autres termes, quels sont les critères d'admissibilité sous-jacents à l'utilisation de la preuve d'identification par ADN?(B)

\section{A- État actuel de l'admissibilité de la preuve d'identification par ADN}

Dès son apparition devant les juridictions civiles et pénales, la preuve d'identification par ADN fut traitée en Grande-Bretagne et aux États-Unis comme une preuve de témoignage scientifique ${ }^{52}$. Certains tribunaux américains

50. Charte canadienne des droits et libertés, partie I de la loi constitutionnelle de 1982 (annexe B de la loi de 1982 sur le Canada (1982), R.U., c.11) art. 11.

51. Voir Jacques BELLEMARE et Louise VIAU, Droit de la preuve pénale, Éditions Thémis, 1992, pp. 110-237; Voir aussi Roger E. SALHANY, A Basic Guide to Evidence in Criminal Cases, 2 éd. Carswell Publication, 1991, pp. 1-25; Jacques FORTIN, Preuve pénale, Éditions Thémis, Montréal, 1984, pp. 40-85.

52. Edward J. IMWINKELRIED, «The Evolution of the American Test for the Admissibility of Scientific Evidence», (1990) 30 Med.Sci.Law, p. 60. 
adoptèrent la doctrine de Frye $e^{53}$ dont ils estimèrent les critères d'admissibilité appropriés $^{54}$ mais bien vite d'autres cours se tournèrent vers les règles plus souples de pertinence définie à travers les règles fédérales de la preuve adoptées en $1972^{55}$. Au Canada, nous ne trouvons aucune jurisprudence adoptant explicitement le principe de Frye lors de l'admissibilité d'une preuve scientifique, même si en 1984 la Commission de réforme du droit du Canada a penché pour la doctrine suivante :

«...la recevabilité même des différents résultats des méthodes d'investigation, sur lesquels sont basées les opinions scientifiques des experts, peut dépendre notamment de leur degré de précision scientifique... Nous pensons que les méthodes qui ne répondent pas aux critères énoncés dans l'affaire Frye devraient être mises en doute» $^{56}$.

Ce vigoureux plaidoyer pour la doctrine de Frye nous amène à nous interroger (1) sur cette théorie, (2) sur l'utilité en matière de preuve d'identification par ADN de la théorie classique de la pertinence.

\section{1- La théorie de Frye}

La principale assertion soutenue dans l'arrêt Frye est la théorie de l'acceptation générale scientifique. Cette théorie a suscité de nombreuses

53. $\quad$ Frye v. United States, 293 F. 1013 (1923).

54. Anthony PERSALL, «DNA Printing : the Unexamined "Witness" in Criminal Trials», (1989) 77 California Law Review, 665, p. 689.

55. Mark J. FUHRMAN, op. cit., note 26, p. 9; l'auteur cite la cause Coppolino v. State 223 So. 2d 68 (Fla. Dist. ct. App. 1968) où on a reconnu la discrétion du juge à admettre une nouvelle preuve scientifique à condition de ne pas abuser de cette discrétion; Edward T. BLAKE «Scientific and Legal Issues Raised by DNA Analysis» in J. BALLANTYNE, G. SENSABAUGH et J. WITKOWSKI, DNA Technology and Forensic Science, 32 Banbury Report, 1990, p. 109. Voir aussi les articles 401, 402, 403, 702 et 703 du Federal Rules of Evidence dans John C. KLOTTER, Criminal Evidence, 5ème édition, Cincinnati, Anderson Publishing Co., 1992, pp. 681, 688-689.

56. COMMISSION DE RÉFORME DU DROIT DU CANADA, Les méthodes d'investigations scientifiques, document de travail 34, 1984, p. 27. 
critiques, car l'acceptation générale d'une technique par la communauté scientifique ne donne pas l'assurance de sa fiabilité ${ }^{57}$.

\subsection{La théorie de l'acceptation générale scientifique}

Dans l'arrêt Frye, une affaire de meurtre où le détecteur de mensonge fut utilisé comme méthode d'investigation, la cour a énoncé sa théorie en matière d'admissibilité d'une preuve scientifique : toute preuve basée sur une nouvelle technique scientifique ne doit être admissible que s'il y a acceptation générale de la technique par la communauté scientifique qui l'utilise. Le libellé de cette théorie reste cependant bien difficile à saisir. En effet, que recouvre l'acceptation générale? Est-ce l'unanimité de tous les scientifiques? Quelle est la discipline ou la spécialité pertinente qui devrait être retenue pour les analyses génétiques: est-ce celle de la biologie moléculaire, de la biochimie, de la génétique démographique ou d'une catégories d'experts connus comme généticiens de la population $^{58}$ ? Dans les procédures criminelles, les échantillons prélevés sur les lieux du crime pouvant être contaminés, devrait-on exiger l'approbation des scientifiques en biologie environnementale quant à la fiabilité des résultats obtenus de tels échantillons? La lecture de la cause canadienne $R$. c. Parent ${ }^{59}$ semble militer pour une approche globale du champ d'expertise qui sera celui retenu par le procureur du ministère public avec le consentement de la défense. Une autre question mérite d'être soulignée : à quel niveau situer l'acceptation générale? Au niveau de la théorie, des techniques et expérimentations ou des trois? Selon un tribunal américain ${ }^{60}$, l'acceptation générale ne signifie pas que la technique soit connue de toute la communauté scientifique, mais seulement qu'elle soit reconnue généralement comme fiable. Cette approche de l'admissibilité fut adoptée par plusieurs tribunaux dans des causes d'identification génétique aux États-Unis ${ }^{61}$. D'autres tribunaux l'interprétèrent plus largement en y ajoutant l'exigence d'impartialité; ce fut la règle Frye-

57. Voir State of New York v. Castro, 545 N.Y.S. (2d) 986 (1989).

58. People v. Wesley, 140 Misc. (2d) (1988).

59. [1988] A.J. n 1125 , (Alta Q.B.), non rapporté.

60. State of New York v. Castro, précitée, note 57.

61. State of Maryland v. Cobey, 80 M.D. App. 31, 559 (1989); People v. Wesley, précitée, note 58; People v. Bailey, 140 Misc. (2d) 317 (1988); State v. Schwartz, 447 N.W. (2d) 422 (1989). 
Kelly $^{62}$. Cependant, dans l'ensemble, la théorie de Frye fut rejetée par beaucoup d'autres, qui trouvèrent l'expression acceptation générale trop laxiste et la théorie de Frye vague et difficile à appliquer ${ }^{63}$.

\subsection{Le rejet de la théorie de Frye}

De nombreux reproches furent adressés au test de Frye en ce sens qu'il représente une abdication de la responsabilité judiciaire ${ }^{64}$. Comme l'écrit un auteur canadien, «la doctrine de Frye donne à la communauté scientifique et non à la communauté légale, le dernier mot de l'admissibilité» ${ }^{65}$. De même, le critère de Frye ne dit rien sur le degré d'acceptation générale dont on a besoin pour établir la fiabilité de la technique (acceptation majoritaire ou unanime?). Selon le professeur Gianelli, le critère de Frye masque les problèmes cruciaux relatifs à l'utilisation d'une technique spécifique en se focalisant surtout sur le point de l'acceptation générale ${ }^{66}$.

Les tribunaux canadiens, malgré la recommandation favorable de la Commission de réforme du droit du Canada (comme nous l'avons mentionné plus haut), ne retinrent pas le test de Frye ${ }^{67}$. Il va de soi que de prime abord la

62. People v. Kelly, 17 Cal. (3d) 24 (1976) : en vertu de la règle Frye-Kelly, la technique doit être non seulement généralement acceptée et fiable mais encore l'expert doit être aussi bien qualifié pour donner une opinion qu'impartial.

63. Patrick KNOLL, «Parent : An Auspicious Beginning for DNA Genotyping in Canada», (1989) 65 Alta. L. R. (2d), p. 29.

64. Pour les critiques, voir Alisa P. ADEMA, «DNA Fingerprinting Evidence : The Road to Admissibility in California», (1989) 26 San Diego Law Review, pp. 397-398; Janet C. HOEFFEL «The Dark Side of DNA Profiling : Unreliable Scientific Evidence Meets the Criminal Defendant», (1990) 42 Stanford Law Review, pp. 506-507; Lorne T. KIRBY, DNA Fingerprinting : An Introduction, W.H.Freeman and Company, New York, 1992, pp.196199.

65. John WALSH, «Legal Issues of Identification : A Canadian Perspective», (1990), communication donnée au mini symposium sur l'ADN organisé par la Société canadienne des sciences judiciaires», Ottawa, p. 156: «Frye gives the scientific community, not the legal community, the last word on admissibility» (traduction).

66. GIANNELLI, «The Admissibility of Novel Scientific Evidence : Frye v. United States, a Half-Century Later», (1980) 80 Colum.1.Rev. p. 1197.

67. R. c. Medvedew (1978) 43 C.C.C. [2d] 434, 6 C.R. (3d) 185 (Man. C.A.) : une cause concernant l'empreinte vocale. Il est bon de mentionner ici la dissidence du Juge O'Sullivan qui opta pour le test de Frye qu'il estime plus en conformité avec les principes de Common Law. Voir aussi R. c. Béland [1987] 2 R.C.S. 398 : le juge Wilson, dissident, en 
règle fondamentale s'applique, soit l'admissibilité de toute preuve pertinente au litige $^{68}$. Toutefois, la pertinence ne suffit pas toujours. Le juge peut exclure cette preuve si son effet préjudiciable l'emporte substantiellement sur sa valeur probante ${ }^{69}$. Cette preuve ne doit pas non plus être obtenue en violation d'un droit garanti par la Charte. Dans ce dernier cas, il faudra appliquer l'article 24 (2) de celle-ci ${ }^{70}$. C'est ce qui ressort des arrêts récents de la Cour suprême du Canada qui a statué que le juge a le pouvoir discrétionnaire pour exclure la preuve si l'équité du procès est mise en cause ${ }^{71}$.

\section{2- La théorie de la pertinence}

La pertinence est une affaire de logique; elle «s'applique à tous les moyens de preuve; elle régit tout autant la preuve écrite ou testimoniale que la preuve relative aux objets trouvés en la possession de l'accusé». ${ }^{72}$ C'est «tout ce qui est en accord avec le bon sens» ${ }^{73}$. Dans l'arrêt Corbett $^{74}$, le juge La Forest écrit : «le principe de pertinence contribue à assurer un procès équitable dans le cadre duquel justice est rendue». Le fait pertinent permet à une personne raisonnable de croire à l'existence ou à la non-existence d'un élément de l'infraction. Selon le juge Sopinka, «la pertinence dépend beaucoup des autres éléments de preuve et des autres points en litige dans une affaire ${ }^{75}$. $《 C$ 'est un facteur fondamental à l'appréciation de la force probante du moyen offert» ${ }^{76}$ que le juge se doit d'examiner en vertu de son pouvoir discrétionnaire.

s'interrogeant sur le test de Frye écrit : «le critère de l'acceptabilité générale posé dans l'affaire Frye a maintenant cédé le pas aux États-Unis à celui de fiabilité raisonnable».

68. Une preuve pertinente est une preuve susceptible de faire avancer une enquête, de permettre «au juge et au jury de découvrir la vérité et de bien trancher les questions en litige» $: R$. c. Seaboyer, [1991] 2 R.C.S. 577.

69. R. c. Potvin, [1989] 1 R.C.S. 525.

70. Ce paragraphe 24(2) prévoit que les éléments de preuve obtenus dans des conditions qui portent atteinte aux droits et libertés de la Charte «seront écartés s'il est établi, eu égard aux circonstances, que leur utilisation est susceptible de déconsidérer l'administration de la justice».

71. R. c. Potvin, précitée, note $69 ; R$. c. Seaboyer, précitée, note 68.

72. Cloutier c. La Reine, [1979] 2 R.C.S. 709.

73. Peter K. McWILLIAMS, Canadian Criminal Evidence, 3ème édition, Toronto, Canada Law Book, 1988, pp. 3-5.

74. R. c. Corbett, [1988] 1 R.C.S. 670.

75. R. c. Morin, [1988] 2 R.C.S. 345.

76. Jacques FORTIN, op. cit., note 51, p 48. 


\subsection{La discrétion judiciaire}

Différentes interprétations découlent de ces termes «discrétion judiciaire». Pour plusieurs, il s'agit d'une certaine liberté de choix individuel laissée au juge du procès d'exclure une preuve admissible. D'autres y voient le pouvoir de rendre des jugements définitifs quant aux questions de faits. Certains, enfin, insistent sur les éléments subjectifs, intuitifs, imaginatifs et 

Les enjeux de la recevabilité
(1994) 24 R.D.U.S.
de la preuve d'identification par $A D N$

émotionnels de la discrétion ${ }^{77}$. La discrétion est une question de degré puisque chaque décision judiciaire implique un choix. La difficulté à résoudre se trouve au niveau du degré de choix. Selon les arrêts Seaboyer ${ }^{78}$ Potvin $^{79}$ et Sweitzer ${ }^{80}$, le juge peut écarter une preuve admissible si son effet préjudiciable l'emporte substantiellement sur sa valeur probante alors que les arrêts $\mathrm{Morris}^{81}$ et $\mathrm{Wray}^{82}$, suggéraient plutôt une interprétation étroite du pouvoir judiciaire avec deux éléments à considérer : une valeur probante minime et un effet préjudiciable élevé. Ce pouvoir discrétionnaire du juge est modifié par la Charte canadienne.

\subsection{L'impact de la Charte}

Il n'est pas sans intérêt de rappeler que la Charte canadienne joue un rôle central dans le droit criminel et particulièrement dans l'admissibilité d'une preuve qui aurait été obtenue en violation d'un droit garanti. En effet, l'article 24(2) de la Charte assure une protection à l'accusé en lui offrant la possibilité de demander l'exclusion de la preuve lorsque des droits ou libertés

77. Pour cette distinction, voir Archie CAMPBELL, «Charter of Rights - S. 24(2)», dans Criminal law and the Charter of Rights and Freedoms - an Update, Department of Education, the Law Society of Upper Canada, Osgoode Hall, Toronto, 1985, p. A-12.

78. R. c. Seaboyer, précitée, note 68.

79. R. c. Potvin, précitée, note 69.

80. Sweitzer c. R., [1982] 1 R.C.S. 525.

81. Morris c. R., [1983] 1 R.C.S. 190.

82. R.c. Wray, [1971] R.C.S. 272; le principe de cet arrêt ne représente plus l'état de notre droit en matière d'admissibilité. 
garantis par la Charte ont été enfreints. Dans l'arrêt Collins ${ }^{83}$, la Cour suprême du Canada a énoncé une liste non exhaustive des facteurs pertinents qui pourraient aboutir à la déconsidération de la justice. Ce sont «les facteurs reliés à l'équité du procès, les facteurs qui se rapportent à la gravité de la violation et les facteurs qui concernent l'exclusion de la preuve» ${ }^{84}$. La déconsidération de l'administration de la justice est examinée selon la norme de la personne raisonnable ${ }^{85}$, objective et bien informée de toutes les circonstances de l'affaire ${ }^{86}$. La nature de la preuve est aussi importante dans l'appréciation de la déconsidération; ainsi l'obtention d'une preuve matérielle en violation d'un droit de l'accusé n'affectera pas généralement l'équité du procès puisqu'elle existe indépendamment de la violation de la Charte $^{87}$ alors que la preuve «autoincriminante» sera généralement rejetée si elle est obtenue dans l'irrespect d'un droit inscrit à la Charte ${ }^{88}$. C'est à l'accusé qu'incombe la charge de prouver la violation ou la négation de l'un des droits garantis par la Charte, s'il veut se prévaloir des dispositions de l'article 24(2). Cette preuve doit se faire selon la règle de la prépondérance de probabilités ${ }^{89}$. Quant à la nécessité d'un lien temporel entre l'obtention de la preuve et la violation d'un droit, la Cour suprême, dans l'arrêt Strachan, déclare qu'elle «n'est pas déterminante» ${ }^{90}$.

83. R. c. Collins, [1987] 1 R.C.S. 265.

84. Pierre BELIVEAU, Bernard LETENDRE, Précis élémentaire de la preuve pénale, Éditions Thémis, Montréal,1992, p. 40.

85. Voir Archie CAMPBELL, op. cit., note 77, p. A-36 : «L'homme (sic) raisonnable est un homme (sic) de la rue, un homme (sic) ordinaire, prudent, plein de bon sens, intelligent».

86. Voir R. c. Collins, précitée, note 83.

87. R. c. Black, [1989] 2 R.C.S. 138.

88. R. c. Manninen, [1987] 1 R.C.S. 1233.

89. R. c. Collins, précitée, note 83.

90. R. c. Strachan, [1988] 2 R.C.S. 980, p. 1006. 
Les tribunaux canadiens ont aussi fait référence au critère de l'utilité en le reliant à celui de pertinence, reprenant par là même ces critères traditionnels qui «fournissent un moyen de conserver ce qu'il y a de positif dans Frye sans qu'on ait à supporter ses inconvénients» ${ }^{91}$. Ainsi dans l'affaire $R$. v. Doe $e^{92}$, le juge Kurisko en arrive à la conclusion que : «les valeurs que cherche à protéger la théorie de Frye le sont déjà adéquatement par les critères traditionnels de la pertinence et de l'utilité». Il faut ici souligner que pour la preuve d'identification par ADN, nos tribunaux interviennent pour le moment sans avoir de normes précises. Ainsi, dans l'affaire Parent $^{93}$, la première cause relative aux analyses génétiques au Canada, il ne fut même pas question de formuler des critères d'admissibilité, car la preuve fut admise par consentement. Dans Terceira ${ }^{94}$, la cour adopta le critère de «fiabilité raisonnable»; dans $R$. v. Dieffenbaugh ${ }^{95}$, le tribunal opta pour le critère de pertinence et de la véracité. Dans les autres causes canadiennes, on note une tendance des tribunaux pour une évaluation positive de la preuve d'identification par ADN; la pertinence et l'utilité de la preuve pour le juge et le jury sont les critères d'admissibilité applicables au Canada.

\section{B- Critères de pertinence et d'utilité : critères élaborés par la jurisprudence}

Les critères de pertinence et d'utilité sont apparus avec la cause McNally ${ }^{96}$ et ont continué d'être approuvés par nos tribunaux dans des causes

91. R. c. Béland, précitée, note 67.

92. $\quad$ R. v. Doe (1986) 31 C.C.C. (3d) 353. «The values sought to be protected by Frye appear to have been adequately preserved by the exercise of restraint in the use of the more flexible traditional relevancy and helpfulness approach».

93. $\quad R$. v. Parent, précitée, note 59.

94. $\quad R$. v. Terceira, 6 octobre 1992, (Ont. Ct. Gen. Div.), non rapporté : les questions de la technique sont prouvées et donc admissibles alors qu'il existe encore des incertitudes sur la question de population de référence qui de ce fait ne peut être encore admise.

95. (1993) 80 C.C.C. (3d) 97 (C.A. C.B.)

96. R. v. McNally, 4 avril 1989, Ont. D. C, $\mathrm{n}^{\circ} 3751$, non rapporté. 
comme Keenan and Hunt $^{97}$, Bourguignon ${ }^{98}$, Voyne Mathias Baptiste ${ }^{99}$, Légère ${ }^{100}$, Johnston $^{101}$, Singh ${ }^{102}$, Lafferty $^{103}$. Mais dans Johnston, le juge Landom a vite fait d'ajouter que si la pertinence et l'utilité sont appropriées comme critères d'admissibilité, il faudrait cependant, dans certains cas, ajouter un autre critère : à savoir que l'effet préjudiciable de la preuve ne dépasse pas sa valeur probante. Les juges du Québec, quant à eux, réaffirmaient les critères de pertinence et d'utilité notamment dans les causes de Santerre ${ }^{104}$, Dorion ${ }^{105}$ et Trottier $^{106}$. À l'heure présente, les décisions ont été dans l'ensemble ${ }^{107}$ rendues en première instance. La fiabilité de la méthode réussira-t-elle à convaincre tous les tribunaux d'appel de son admissibilité? On peut penser que l'intervention de ceux-ci contribuerait à asseoir des critères appropriés d'admissiblité et que la preuve d'identification par ADN ne sera pas menacée de prohibition absolue comme la méthode du polygraphe ${ }^{108}$.

Nous ne voulons pas reprendre ici en détail la question relative à la pertinence de la preuve. Nous mentionnerons tout simplement que pour la preuve d'identification par ADN, l'appréciation de la pertinence se fait compte tenu de la connexité entre les faits que l'on veut prouver et le crime qui est reproché. Il est donc primordial d'établir avec certitude le lieu de provenance des échantillons utilisés pour les analyses (ceux qui appartiennent au suspect et ceux de la localisation du crime) car l'absence de lien entre la provenance et la question en litige est une cause de non-pertinence. À cette condition de provenance s'ajoute l'exigence de la fiabilité. Si toutes ces conditions sont

97. $\quad R$. v. Keenan and Hunt, 11 décembre 1990, (Ont. C.), non rapporté.

98. $\quad R$. v. Bourguignon, 14 janvier 1991, (Ont. C.), non rapporté.

99. R. v.Voyne Mathias Baptiste, 14 mars 1991, 38 (C.S.C.-B), non rapporté. L'honorable juge Hamilton écrit : «..where it is relevant and would be hepful to the jury, the evidence should be admitted.»; 10 février 1994 (C.A.C.-B.), non rapporté.

100. $\quad R$. v. Légère, 29 août 1991, (C.B.R.N.-B.), non rapporté.

101. R. v. Johnston,(1992) 69 C.C.C. (3d) 395 (Ont. Ct. Gen. Div.).

102. $\quad R$. v. Gary Singh, 1er avril 1993, (C.S.C.-B.), non rapporté.

103. $\quad R$. v. Lafferty, [1993] N.W.T.J. $\mathrm{n}^{\circ} 17$.

104. R. c. Santerre, 23 octobre 1991, Cour Supérieure, n 500-01-017961-902, non rapporté.

105. R. c. Dorion, 17 décembre1992, Cour Supérieure, $\mathrm{n}^{\circ}$ 500-01-019135-919, non rapporté.

106. R. c. Trottier, octobre 1992, Cour Supérieure, $\mathrm{n}^{\circ}$ 500-01-25883-908, non rapporté.

107. Une première décision fut déjà rendue en appel; Voir R. v.Voyne Mathias Baptiste, précitée, note 99.

108. Voir $R$. v. Béland, précitée, note 67. 
réunies, la preuve d'identification par ADN passera pour pertinente au regard du droit pénal canadien. Cependant, si pertinente qu'elle soit, son utilité(1) doit être démontrée au juge et au jury qui devront être convaincus de sa force probante (2).

\section{1- Utilité comme preuve matérielle et comme témoignage d'expert}

La preuve d'identification par ADN appartient à la fois à la catégorie des preuves matérielles et à celle des preuves d'opinion et doit démontrer son utilité par rapport à ces deux moyens de preuve ${ }^{109}$. C'est au juge d'être convaincu de l'utilité qu'apporterait cette preuve au jury, mais ce serait à ce dernier de décider de sa force probante ${ }^{110}$. La preuve doit permettre au juge et au jury de découvrir la vérité. Sa haute complexité technique nécessite l'assistance d'un expert pour aider le juge et le jury à prendre une décision éclairée. C'est au juge de décider, au cours d'un voir-dire, de la présentation ou non de la preuve au jury. Pour cela il doit tenir compte de la compétence et de la qualité de l'expert et s'assurer que le jury soit capable d'évaluer la force probante de preuve présentée $^{111}$.

\section{2- Valeur probante de la preuve}

La présentation d'une preuve matérielle qu'est l'échantillon biologique est un moyen de preuve privilégié. La technologie a permis de conserver trace de ces éléments matériels, cependant les résultats sont tributaires de l'interprétation de l'expert. Par ailleurs, il existe une zone grise provenant de la rapidité des développements technologiques dans ce domaine qui crée une incertitude et de ce fait contribue à discréditer les probabilités affirmées dans le cadre de la preuve d'identification par ADN. Néammoins, on peut s'attendre à ce que les analyses génétiques aient une très grande incidence sur les taux de

109. La preuve d'identification par ADN ne peut être utile au jury que si l'aspect technique est exposé au jury par un expert qualifié.

110. $\quad R$. v. McNally, précitée, note 96.

111. Marie LUSSIER, «Genes and Canadian Criminal Law», 199271 R. du B. Can, p. 344. 
condamnations $^{112}$. En effet, bien souvent la nature de la preuve peut emporter la conviction du juge et des jurés même s'ils ne sont pas liés par le résultat de l'expertise. «Plus la technique est complexe, plus la confiance des jurés pourra être aveugle» ${ }^{113}$, car ceux-ci pourraient accorder une valeur probante à cette technique et aux probabilités statistiques sans analyser la qualité et la fiabilité de la méthode. Il importe donc de prémunir le système judiciaire contre l'auréole d'une preuve scientifique car le but ici recherché est l'établissement de la vérité. L'admissibilité de cette preuve comme témoignage d'expert usurperait-elle les fonctions du juge et des jurés et aboutirait-elle au renversement du fardeau de la preuve et à la destruction de la présomption d'innocence?

\subsection{Probabilité et langage}

Le langage est bien souvent une cause d'incompréhension entre juristes et scientifiques, ce à cause du particularisme de langage de chaque discipline. En matière de preuve d'identification par ADN, il semble donc important d'examiner les définitions du terme probabilité. Pour le scientifique qu'est l'expert, la probabilité équivaut quasiment à une certitude, soit jusqu'à $99 \%$, alors que le juriste s'attache à une «certitude raisonnable», car n'oublions pas qu'en matière pénale le droit exige une preuve hors de tout doute raisonnable avant de condamner, et que le moindre doute doit profiter à l'accusé. Quelle est donc la portée de la probabilité employée par les scientifiques pour établir la certitude de leur identification? Avec les statistiques faramineuses des experts, le jury peut être déconcerté par ce terme qui dénote une certitude irréfutable et ne laisse aucune place à l'appréciation des autres éléments. Dans plusieurs causes d'analyses génétiques la question s'est posée. Selon le juge Flanigan, dans la cause Bourguignon ${ }^{114}$, le témoignage de l'expert concernant les tests et les techniques est admissible comme une question de fait pour le jury, mais inadmissible en droit lorsqu'il est relié à la statistique des probabilités, opinion rejetée par le juge Hamilton dans la cause Baptiste ${ }^{115}$ :

112. Voir LIFECODES CORPORATION, Test d'identification des empreintes génétiques de l'ADN : renseignements généraux, 1986, p. 17.

113. Pierre PATENAUDE, La preuve, les techniques modernes et le respect des valeurs, Revue de droit Université de Sherbrooke, 1990, p. 147.

114. R. v. Bourguignon, précitée, note 98.

115. $\quad R$. v. Baptiste, précitée, note 99. 
Les enjeux de la recevabilité
(1994) 24 R.D.U.S. $\quad$ de la preuve d'identification par ADN
dans le système pénal canadien

«toutes questions relatives aux points faibles de l'interprétation ou des limites des banques de données sont, à mon avis, des questions qui doivent être analysées et pesées ensemble par le jury avec tous les autres éléments de preuve».

Le juge doit donc prendre tous les moyens pour se prémunir contre l'erreur scientifique et instruire le jury en conséquence, car les statistiques démontrant une forte probabilité d'identification ne permettent pas automatiquement de conclure à la culpabilité de l'accusé. Devrait-on aller jusqu'à interdire à l'expert de citer les statistiques?

\subsection{Preuve hors de tout doute raisonnable}

La culpabilité de l'inculpé doit être prouvée «hors de tout doute raisonnable» eu égard à chacun des éléments de l'infraction, la preuve de l'identification étant une preuve indirecte. En vertu du principe de la présomption d'innocence, principe qui se trouve au centre du droit criminel, le fardeau de la preuve repose sur les épaules de la couronne. Ainsi le juge Dickson, dans l'arrêt Oakes $^{116}$, déclare que

«... le droit, prévu par l'al. 11 d), d'être innocent tant qu'on n'est pas déclaré coupable exige à tout le moins que, premièrement, la culpabilité soit établie hors de tout doute raisonnable et, deuxièment, que ce soit à l'État qu'incombe la charge de la preuve.»

C'est donc à une «justice de conviction» que sera soumis l'accusé. Si un doute raisonnable subsiste soit sur les éléments du crime soit sur la crédibilité de la preuve (même si c'est une preuve d'identification par ADN), le juge et le jury ne pourraient rendre qu'un verdict de non-culpabilité.

Comme nous le mentionnons plus haut, les analyses génétiques semblent satisfaire aux objectifs du système pénal, c'est-à-dire faire éclater la vérité en établissant avec un haut degré de certitude la culpabilité ou l'innocence, protéger la société et réduire la criminalité. Il n'en demeure pas moins que leur remarquable spécificité nous met face à des perspectives inquiétantes. En effet, 
les désirs de vérité et de prévention pourraient amener quelquefois à la violation des valeurs fondamentales. Avec l'informatisation des données, cette preuve biologique pourrait même être employée comme un moyen de contrôle social ${ }^{117}$ si l'on se fonde sur la thèse du déterminisme génétique ${ }^{118}$. Face à ces dangers, il nous semble opportun d'analyser le risque de l'utilisation de cette preuve sur nos droits fondamentaux et de nous interroger sur la capacité du droit à assurer la dignité humaine.

\section{III- LA PREUVE D'IDENTIFICATION PAR ADN ET LES DROITS ET LIBERTÉS}

Comme toute autre technologie scientifique, la preuve d'identification par ADN pose le dilemme suivant : le savoir et le pouvoir confrontés aux garanties des droits de la personne et de la justice sociale. En effet, avec l'analyse génétique, c'est la personne toute entière qui est l'enjeu de pouvoirs; la personne dans sa dimension physique, dans sa dimension humaine et sociale, la personne dans sa dimension cosmique.

La preuve obtenue par analyse génétique semble être porteuse de bénéfices notables pour la justice dans le domaine de l'identification; mais il ne fait nul doute que l'utilisation de cette preuve sans un contrôle efficace générera de nombreux problèmes. Les risques et les atteintes à la dignité humaine peuvent se multiplier (atteinte aux droits fondamentaux renforcés par les problèmes liés à la collecte et l'utilisation des échantillons, l'informatisation et la création des banques de données, les questions de sécurité génétique, les questions de coût, les questions de répercussion familiale et sociale etc...). Les implications sociales sont très graves à cause du caractère intrinsèque du matériel utilisé.

117. Ne pourrait-on pas imaginer qu'un gouvernement collecte des renseignements génétiques personnels au moyen des tests d'analyse génétiques afin de découvrir des caractéristiques asociales chez certaines personnes, caractéristiques qui les prédisposeraient au crime? Ces «mésadaptés sociaux» seraient étiquetés et feraient l'objet de surveillance accrue : Voir D. SUZUKI et P. KNUTDSON, Genethics : The Ethics of Engineering Life, Stoddart, 1988, pp. 151-152.

118. Bartha Maria KNOPPERS, Dignité humaine et patrimoine génétique, Commission de réforme du droit du Canada, Document d'étude, 1991, pp. 47-50 : le déterminisme génétique sous-entend que l'individu est ce qu'il est à cause de ses gènes. 
Des textes constitutionnels tels la Charte canadienne ${ }^{119}$ ou quasiconstitutionnels comme la Charte québécoise ${ }^{120}$ garantissent des droits et libertés qui ne «peuvent être restreints que par une règle de droit» ${ }^{121}$. Mais il faudrait songer dès maintenant à fixer les limites de l'utilisation de la technique, à dispenser de l'information adéquate à toute la société et à l'amener à faire des choix responsables pour une justice sociale. Dans une société libre et démocratique le respect de la dignité de l'être humain (A) est un droit fondamental. Pour cela, nous devons nous diriger vers un encadrement adéquat de l'usage de cette technique (B).

\section{A- $\quad$ Le respect de la dignité humaine}

La dignité humaine est

«considérée comme le fondement du droit à la vie, à la liberté et à la sécurité de la personne, du droit à la protection contre les fouilles, les perquisitions et les saisies abusives, du droit à l'égalité et du droit à la protection contre la discrimination énoncés dans la Charte canadienne des droits et libertés» ${ }^{122}$.

Cette dignité s'exprime non seulement à travers les droits fondamentaux (1), mais aussi à travers les droits de la défense (2). En effet, «tous les droits de l'homme découlent du respect de cette dignité inhérente» ${ }^{123}$.

\section{1- Les droits fondamentaux}

Les droits qui sont les plus souvent remis en cause par les analyses génétiques sont les garanties applicables pendant la phase précédant le procès et particulièrement pendant les enquêtes policières. Cependant, avec la mise en banque des échantillons et l'informatisation des données, les violations s'étendent aussi à la phase postérieure au procès; ces violations ne touchent plus

119. Charte canadienne, précitée, note 50.

120. Charte des droits et libertés de la personne, L.R.Q., c. C-12.

121. Charte canadienne, précitée, note 50, art.1.,

122. Bartha Maria KNOPPERS, op. cit., note 118, p. 2.

123. Id, p. 26. 
au suspect ou à l'accusé uniquement, mais encore à ses proches et à son patrimoine génétique. Des garanties juridiques protègent l'individu contre ces invasions qui peuvent êtres physiques, psychiques ou familiales.

\subsection{Le droit à l'intégrité}

Ce droit découle du droit à la vie, à la liberté et à la sécurité protégé par l'article 7 de la Charte canadienne, du droit à la protection contre les fouilles et les perquisitions ou les saisies abusives de l'article 8 de la même Charte et du droit à la dignité énoncé dans l'article 5 et 8 de la Charte québécoise. La liberté individuelle suppose le droit au respect de son intégrité physique. Ainsi, nul ne doit être soumis à des prélèvements sans son consentement, à moins que la loi ne l'y oblige ${ }^{124}$.

Les échantillons biologiques qui serviront à la constitution de la preuve d'ADN sont donc un élément déterminant de l'intégrité de la personne humaine et sont protégés contre toute atteinte arbitraire. Par conséquent, les suspects doivent donc donner leur consentement pour un prélèvement et l'inobservance de cette condition peut être considérée comme une saisie et entraîner l'exclusion de ces éléments de preuve ${ }^{125}$. Selon le juge La Forest, la distinction entre une saisie et la simple réunion d'éléments de preuve se situe au point où il devient raisonnable de dire que l'individu n'a plus d'intérêt intime relatif à l'objet qui serait saisi» ${ }^{126}$. Ainsi, dans la cause Dyment, la saisie par un policier d'un échantillon de sang recueilli par le médecin pour des causes médicales et sans le consentement de l'appelant a été jugée illégale sous l'article 8 de la Charte canadienne ${ }^{127}$.

124. Voir les articles 256 à 258 du Code criminel et l'article 2 de la Loi sur l'identification des criminels.

125. R. v. Stillman, 8 mars 1993, (C.B.R. N.-B.), non rapporté : les échantillons de poils et de cheveux rélevés malgré les objections de celui-ci ont été jugés illégalement obtenus.

126. R. v. Dyment, [1988] 2 R.C.S. 417.

127. Id. Selon le juge La Forest, «l'article 8 ne vise pas uniquement à protéger la propriété, mais aussi les intérêts privés en matière de vie privée contre les fouilles, les perquisitions et les saisies». Voir aussi R. v. Pohoretsky, [1987] 1 R.C.S 945. Voir aussi R. c. Dersch, [1993] 3 R.C.S. 768 : la transmisssion à la police des prélèvements recueillis par un médecin à des fins médicales est assujettie à la charte. 
En matière d'analyses génétiques, il n'y a pas lieu de faire la distinction entre prélèvements internes ou externes, prélèvements intimes ou non intimes comme l'énonce en Grande Bretagne l'article 65(1) du Police and Criminal Evidence $A c t^{128} \mathrm{de} 1984$, car, en principe, tous les éléments biologiques contiennent le code génétique de l'individu. Leurs saisies sans consentement, contrairement à ce qui a été décidé pour les empreintes digitales ${ }^{129}$, constituent une violation qui enfreint l'article 7 de la charte ${ }^{130}$. Qu'en est-il des substances corporelles abandonnées qui peuvent être réunies par la police dans le cadre de la réunion d'éléments de preuve? Selon la Charte, lorsqu'une personne cesse d'avoir une expectative raisonnable de vie privée sur une substance corporelle, ses droits ne peuvent être enfreints au regard de cette substance. Ainsi, la réunion de ces éléments ne constitue nullement une violation ${ }^{131}$. Pour un accusé détenu, «même si la réunion d'échantillons biologiques peut présenter une petite difficulté» ${ }^{132}$, cela ne pourrait être assimilé à une saisie et fouille abusive, car cela ne viole pas le droit à une expectative raisonnable de la vie privée si la fouille a été conduite de bonne foi et non dans un dessein de châtiments ${ }^{133}$. Selon la jurisprudence, le respect de la vie privée est moins garanti à l'intérieur d'une prison que dans la vie ordinaire car les perquisitions et inspections sont très fréquentes et nécessaires dans une prison de sécurité maximum ${ }^{134}$. Cependant, comme le fait remarquer le juge MacKay dans l'affaire Jackson ${ }^{135}$, même si la

128. Police and Criminal Evidence Act, 1984, Code of Practice (second edition 1991) : les prélèvements non intimes sont possibles sans le consentement de l'intéressé, mais sur ordre d'un superintendant, alors que pour les prélèvements intimes, en plus de l'assentiment du superintendant il faut le consentement écrit de l'individu.

129. R.c. Beare \& Higgins et al., (1989) 66 C.R. (3d) 97.

130. $\quad R$. v. Légère, (1988) 43 C.C.C. (3d) 502.

131. R. v. Stillman, précitée, note 125 : la police a récupéré dans une poubelle une serviette en papier contenant du mucus, le suspect s'étant mouché avec celle-ci pendant son arrestation. L'échantillon de mucus, a été jugé légalement recueilli. Voir aussi $R$. v. Légère, 29 août 1991 (C.B. N.-B.), non rapporté : le suspect, s'étant légèrement blessé pendant son arrestation, s'est essuyé le nez avec un mouchoir en papier qu'il a ensuite jeté à la poubelle. Le spécimen de sang recueilli sur le mouchoir en papier récupéré par la police est admissible.

132. Patrick KNOLL, loc. cit., note 63, pp. $34:$ «...where an accused person is detained the gathering of some of this evidence may present little difficulty.»

133. Re Soenen and Thomas et al (1984) 8 C.C.C. (3d) 224 (Alta QB).

134. Warriner v. Discplinary Tribunal of Kingston Penitentiary, 7 décembre 1990, $\mathrm{n}^{\circ}$ T- 963-89 (non rapporté); voir aussi Weatherall v. AG Canada et al, Conway v. The Queen, Spearman v. Disciplinary Tribunal Bay Penitentiary et al, (1989) 59 CR (3d) 247.

135. Jackson v. Joyceville Penitentiary Disciplinary Tribunal, (1990) 55 C.C.C. (3d) 50. 
vie privée est limitée pour les prisonniers, il n'en reste pas moins que les droits de ceux-ci ne peuvent être restreints qu'en accord avec les principes de justice fondamentale.

Quant au consentement exigé pour un prélèvement, il doit être libre et éclairé $^{136}$. La personne qui accepte le prélèvement ne doit avoir subi aucune pression d'ordre psychologique, socio-économique ou physique. Le droit pénal n'exige aucune formalité précise pour le consentement, il suffit que celui-ci soit valide $^{137}$. Cependant la validité du consentement ne fait pas disparaître l'expectative de la vie privée qu'aura un individu «dans le contexte informationnel ${ }^{138}$ ».

\subsection{Le droit à la vie privée}

Le droit à la vie privée est un droit fondamental de l'individu, un facteur essentiel à sa dignité. Car comme le mentionne le juge La Forest dans l'arrêt Thomson Newspapers Limited,

«le soupçon qui pèse sur les personnes qui font l'objet d'une enquête criminelle peut compromettre sérieusement et peut-être de façon permanente leur statut dans la collectivité. Cet aspect à lui seul permettrait au citoyen de s'attendre à ce qu'on porte atteinte à son droit à la vie privée seulement lorsque l'État a démontré qu'il a des motifs sérieux de soupçonner qu'il est coupable» ${ }^{139}$.

Toute atteinte à ce droit est grave, comme le déclare le même juge dans Dyment : «l'utilisation du corps d'une personne, sans son consentement, en vue

136. R. c. Rivest, (1990) 20 M.V.R. (2d) 196 (C.Q.). Dans cette cause, les policiers ont obtenu le consentement de l'accusé pour un prélèvement de sang sans lui expliquer la raison de la demande. La cour a jugé que cette preuve doit être exclue en vertu de l'article 24(2) de la Charte, alors que dans la cause $R$. v. Young, 2 novembre 1993 (C.S. T.-N.), non rapportée, bien qu'on n'ait pas précisé au suspect à quelles investigations seraient soumis les échantillons de matériel biologique fournis volontairement, ce consentement a été jugé libre et éclairé.

137. Pour les conditions requises pour un consentement valide, voir R. v. Wills, (1992) 12 C.R. (4 th) 77-78. Voir aussi Jobidon c. La Reine [1991] 2 R.C.S. 714.

138. $\quad R$. v. Dyment, précitée, note 126, p. 428.

139. Thomson Newspapers c. Directeur des enquêtes et recherches, [1990] 1 R.C.S. 425, p. 508. 
d'obtenir des renseignements à son sujet constitue une atteinte à une sphère de la vie privée essentielle au maintien de sa dignité humaine» ${ }^{140}$. Plusieurs textes législatifs et constitutionnels ont consacré explicitement ou implicitement le droit à la vie privée. Ainsi l'article 5 de la Charte québécoise stipule : «toute personne a droit au respect de sa vie privée»; de même on retrouve de façon implicite ce droit dans les articles 7 et 8 de la Charte canadienne, car comme le dit le juge Dickson dans l'arrêt Hunter c. Southam Inc. ${ }^{141}$ «l'objet de l'article 8 est de protéger les attentes raisonnables des citoyens en matière de vie privée». La preuve d'identification par ADN menace la vie privée de l'individu en y faisant des ingérences dans la zone d'intimité. Les atteintes peuvent donc être très graves lorsqu'il y a conservation et stockage des échantillons et des données. Qui devrait avoir accès à ces données sensibles et qui contrôlera leur utilisation? Quelle est la nature des informations susceptibles d'être révélées si on conserve des échantillons biologiques et si on constitue des banques de données?

\subsubsection{La Conservation des échantillons et la constitution des banques de données}

La conservation des échantillons pour une contre-expertise est une obligation si on veut satisfaire aux droits de la défense, surtout si une décision finale n'a pas été rendue. C'est un fondement à l'administration de la justice. On ne peut donc interdire aux autorités policières de colliger et de stocker les échantillons biologiques uniquement parce qu'ils contiennent de l'ADN; l'efficacité même du système pénal en dépend. On ne saurait non plus prohiber ces procédés opérationnels sans gêner l'investigation et le dépistage du crime. Dans la même optique, le but de la centralisation des données est de pouvoir effectuer très rapidement des recoupements entre les empreintes latentes et les caractéristiques génétiques de personnes fichées. Des banques informatisées de données d'empreintes digitales existent déjà et sont efficaces, mais la conservation des échantillons biologiques et l'informatisation des données génétiques peuvent faire craindre des récupérations préjudiciables aux droits de l'individu puisqu'un simple échantillon d'ADN contient toute l'information génétique de l'individu et constitue une partie intime et privée. La question

140. R. v. Dyment, précitée, note 126, p. 431.

141. [1984] 2 R.C.S. 145, p. 149. 
d'accès aux échantillons et de protection des données se pose avec acuité. Stocker des échantillons de matériels génétiques de criminels violents ou de récidivistes, comme il est fait dans l'État de Californie ${ }^{142}$ semble très pertinent, mais des mesures doivent être adoptées pour assurer leur protection, la confidentialité de l'information et la résistance à des influences extérieures. Il faut empêcher des personnes peu scrupuleuses d'utiliser les matériaux à des fins autres que judiciaires. Les informations recueillies dans le cadre des enquêtes judiciaires ne doivent donc pas servir à des fins médicales par exemple; cela est inacceptable et va à l'encontre du respect du droit à la vie privée.

Mais, est-ce que les échantillons biologiques fournis par un accusé pour des fins de comparaison peuvent être mis à la disposition de la défense? Dans la cause Guevara ${ }^{143}$, il a été dit que tous les résultats d'échantillons fournis par l'accusé sont soumis au secret professionnel à moins que la défense ne cite à témoigner l'expert qui a effectué l'analyse. Ce raisonnement nous laisse perplexe; en effet, la technique d'identification par ADN est basée sur l'association des profils et consiste à établir les relations entre ces profils; comment alors dévoiler une partie des résultats sans révéler l'autre?

Quant à la preuve résultant d'échantillons biologiques prélevés sur un prévenu qui les a offerts volontairement peut-elle être utililisée contre lui dans des procédures judiciaires ultérieures? Selon la jurisprudence, le privilège de la non auto-incrimination de l'article 13 de la Charte canadienne ne s'applique qu'à l'incrimination testimoniale; elle ne vise pas la preuve physique ou matérielle. Cette interprétation restrictive de l'article 13 de la Charte sera appliquée quant à l'utilisation de la preuve provenant d'une analyse génétique.

En ce qui concerne les banques de données, bien qu'elles soient une aide précieuse pour la police et la justice dans leur souci de protection de la société $^{144}$, elles peuvent cependant constituer un véritable danger non seulement

142. Le Code pénal de Californie (California Pénal Code, (1992), West Publishing Company, para 290.2) ainsi que certaines législations aux États-Unis permettent cette collecte d'échantillons pour fins de constitution de banques de données.

143. $\quad R$. v. Guevara, 7 0ctobre 1993, (C. prov. C.-B.), non rapporté.

144. Aux États-Unis, plusieurs affaires ont été résolues grâce aux banques de données contenant les dossiers génétiques des condamnés. 
pour la vie privée de l'individu, mais aussi pour celle des tiers. En effet, l'information génétique stockée peut intéresser certaines personnes qui veulent avoir des renseignements sur les caractères génétiques d'un individu pour des raisons n'ayant aucun lien avec les enquêtes criminelles. Or, comme nous venons de le voir, «les données génétiques font partie du «domaine réservé», de la «sphère d'intimité» qu'il est au pouvoir de chacun de soustraire au regard, même bienveillant d'autrui» ${ }^{145}$. Tout un chacun est libre de la communiquer ou non. Présentement, la question de mesure à prendre pour assurer une protection efficace de ces banques se pose. Faut-il réglementer la constitution de ces banques, l'accessibilité des données et leur durée de conservation, afin de limiter le risque d'atteinte aux droits de l'individu? Certes, plusieurs textes en droit québécois et canadien peuvent apporter des solutions précieuses sur cette question. Nous faisons allusion au Code civil du Québec ${ }^{146}$, à la Loi sur l'accès aux documents des organismes publics et sur la protection des renseignements personnels $^{147}$, à la Loi sur la protection des renseignements personnels ${ }^{148}$, et à la Loi sur la protection des renseignements personnels dans le secteur privé ${ }^{149}$. Mais ces législations sont insuffisantes et ne régissent ni la gestion des dossiers ni la circulation des renseignements.

145. Francis LERNALEGUEN, «La diffusion intra et inter-familiale de l'information génétique», dans La génétique humaine : de l'information à l'informatisation, Éditions Thémis et Litec, 1992, p. 252.

146. L.Q. 1991, c.64, art. 37 qui requiert de «toute personne qui constitue un dosssier sur une autre personne un intérêt sérieux et légitime».

147. L.R.Q. c. A-2. Cette loi «ne parle pas de dossiers mais de fichiers de renseignements» : voir René LAPERRIÈRE, «La loi sur la protection des renseignements personnels dans le secteur privé - commentaire et guide d'interprétation», dans Vie privée sous surveillance : la protection des renseignements personnels en droit québécois et comparé, Editions Yvon Blais, 1994, p. 151.

148. L.R.C. (1985) c. P-21.

149. L.Q. 1993, c. 17. 


\subsubsection{Le droit à la confidentialité}

La notion de dignité recouvre aussi le respect de la confidentialité des renseignements intimes concernant une personne. Cette confidentialité lui donne le pouvoir de contrôler la circulation de l'information parmi les tiers ${ }^{150}$. Le droit à la confidentialité est non seulement personnel à l'individu, mais protège aussi son patrimoine génique. En effet, avec l'informatisation des données génétiques, on touche à l'identité génétique de la personne; une information enregistrée sur l'ADN est égale non seulement à l'enregistrement du génome tout entier mais elle identifie et a un impact sur la famille. Les problèmes de confidentialité (confidentialité à l'intérieur des relations individus/familles, médecins/patients, citoyens/États) et d'accessibilité aux données restent donc entiers. La conservation des échantillons et des données est donc potentiellement dangereuse et met en jeu la vie et la sécurité de toute sa génération. Le droit à la confidentialité est donc aussi en péril.

\subsection{Le droit à la non-discrimination}

La Charte canadienne dans son article 15(1) énonce le droit à la nondiscrimination en vertu de sa race, son origine nationale ou ethnique...ou de ses déficiences mentales ou physiques. Selon la cour, dans l'arrêt Andrews ${ }^{151}$, «la discrimination est inacceptable dans une société démocratique». L'individu est protégé aussi bien contre la discrimination volontaire et directe que contre celle involontaire et indirecte. La distinction en vertu de son profil génétique ou de son appartenance à une ethnie ou à un sous-groupe porteur de maladie génétique peut-elle être perçue comme une discrimination? En effet, la police pourrait avoir tendance à recueillir des échantillons pour fins de tests d'ADN d'un certain groupe de suspects en fonction de leur race, ce disproportionnellement à leur représentativité dans la société. Déjà en Grande-Bretagne, un commissaire parlementaire a proposé la mise en fiches de tous les hommes adultes pour, soidisant, prévenir les cas d'agressions sexuelles. ${ }^{152}$

150. Hélène GUAY et Bartha M. KNOPPERS, «Information génétique : qualification et communication en droit québécois», (1990) 21 R.G.D. 545, p. 565.

151. Andrews c. Law Society of British Columbia, [1989] 1 R.C.S. 143.

152. Voir G.C., «Les truands trahis par les gènes», L'express, 5 décembre 1991, p. 25. 
(1994) 24 R.D.U.S.

\section{2- $\quad$ Les droits de la défense}

La contre-expertise est l'expression même des droits de la défense. La possibilité d'une contre-expertise peut se déduire de l'article 11 de la Charte canadienne qui énonce le droit à un procès juste et équitable. La question de justice se soulève dans les cas où l'on ne dispose pas d'une quantité d'échantillon appréciable prélevée sur les lieux du crime ou sur la victime; la Couronne serait donc la seule qui pourrait bénéficier de la preuve d'identification par ADN si on utilise la méthode de Southern qui, comme nous l'avons mentionné dans la partie 1, exige une quantité substantielle d'élément biologique. Ainsi, la règle de l'égalité des parties au procès ne sera pas respectée, puisque la défense ne pourra pas effectuer ses propres tests; elle est par conséquent limitée dans sa contreexpertise. Toutefois, on doit tempérer cette affirmation puisque la technique d'amplification génique $(P C R)$ est maintenant intégrée à la technologie d'analyse d'ADN et mise en application dans les laboratoires.

Un autre point mérite d'être évoqué, c'est l'accessibilité économique de la méthode. Le coût du test, variant entre 750 et 1000 \$ par échantillon, peut être un frein pour l'accusé qui ne peut s'offrir les mêmes tests pour une contreexpertise $^{153}$. Ce coût sera augmenté si la défense doit aller en dehors du continent pour faire des tests puisqu'au Canada il n'existe qu'une seule entreprise privée qui est habilitée à faire ces analyses et les demandes pourraient être nombreuses.

L'impossibilité de contre-expertise équivaudrait-elle à une violation du droit à une défense pleine et entière ou affecterait-elle la crédibilité du témoignage puisque l'objet de la contre-expertise vise à garantir la certitude de l'identification et que toute action humaine comporte une marge d'erreur? La réponse n'est pas facile si l'on examine, en procédant par analogies, la jurisprudence citée dans l'ouvrage par le professeur Beliveau ${ }^{154}$ où deux tendances contraires se dégagent : l'une reconnaît que l'impossibilité pour l'accusé de procéder à une contre-expertise était une violation de son droit à une

153. On peut mettre ici un bémol, car l'accusé peut, s'il est éligible, bénéficier de l'aide juridique.

154. Voir Pierre BELIVEAU, Les garanties juridiques dans les Chartes des droits, Editions Thémis, Montréal, 1991, pp. 329-331. 
défense pleine et entière alors que pour l'autre tenant le procès équitable n'est pas du tout affecté.

Par ailleurs, les atteintes aux droits socio-économiques par accès ou par fuite d'informations peuvent se traduire par de la discrimination dans les domaines de l'emploi et de l'assurance. ${ }^{155}$ Ainsi des employeurs peuvent refuser d'engager certaines personnes à cause de leur histoire génétique et des assureurs de les assurer.

Tous ces droits et surtout le respect de la dignité humaine nous amènent à considérer la nécessité d'un encadrement, car l'absence de dispositions claires ne peut favoriser que des abus. Il faut préciser dans quelles limites on devrait être autorisé à utiliser cette méthode qui pourrait porter atteinte aux droits individuels.

\section{B- Nécessité d'un encadrement}

L'élaboration d'un encadrement ne peut être faite sans recueillir des données nécessaires à sa confection au cours d'un débat éthique (1) et en déterminant le contenu à partir d'expériences législatives vécues dans d'autres pays (2).

\section{1- Débat éthique et mécanismes de gestion sociale}

Des préoccupations éthiques ont conduit divers comités à souhaiter une organisation de l'utilisation de la preuve d'identification et à tracer des grandes lignes directrices. Cependant ces tentatives de recommandations ne sauraient être efficaces sans une prise de conscience de tous.

155. Voir Hélène Guay, Bartha M. KNOPPERS et Isabelle PANISSET, « La génétique dans les domaines de l'assurance et de l'emploi», (1992) 52 R.du B., p. 185. 


\subsection{Assises prospectives}

Plusieurs comités éthiques et juridiques ont évalué les risques sociaux soulevés par la méthode de la preuve d'identification par ADN et ont émis des recommandations qui ont commencé à être intégrées dans les systèmes législatifs. Nous citerons comme exemple quelques instances : le Comité Consultatif National d'Éthique français pour ses avis rendus en $1989^{156}$ et en $1991^{157}$, le Conseil National Américain de la recherche pour son rapport concernant la preuve d'ADN en $1992^{158}$, le Conseil de l'Europe pour sa recommandation adoptée en $1992^{159}$, la Commission de réforme du droit du Canada dans son document de travail sur les méthodes d'investigations scientifiques $^{160}$ ainsi que le commissaire à la protection de la vie privée du Canada $^{161}$.

À travers ces textes, on peut dégager implicitement les principes suivants qui inspireront une normativité juridique.

Le droit à l'intégrité se manifestera par une limitation de la preuve d'identification par ADN à des fins judiciaires uniquement et sous le contrôle et l'autorisation du juge; donc, le test ne doit pas être permis à des fins de prévention policière ou de poursuites autres que pénales.

156. COMITÉ CONSULTATIF NATIONAL D'ÉTHIQUE POUR LES SCIENCES DE LA VIE ET DE LA SANTÉ, «Avis relatif à la diffusion des techniques d'identification par analyse de l'ADN (technique des empreintes génétiques)», Paris, 15 décembre 1989.

157. COMITÉ CONSULTATIF NATIONAL D'ÉTHIQUE POUR LES SCIENCES DE LA VIE ET DE LA SANTÉ, «Avis relatif à l'application des tests génétiques aux études individuelles, études familiales et études de populations (problème des banques d'ADN de cellules et de l'informatisation des données)», Paris, 24 juin 1991.

158. NATIONAL RESEARCH COUNCIL, Committee on DNA Technology in Forensic Science, DNA in Forensic Science, National Academy Press, Washington, (1992).

159. CONSEIL DE L'EUROPE, Comité des ministres, Recommandation $\mathrm{N}^{\mathrm{o}} \mathrm{R}$ (92) 1 sur l'utilisation des analyses de l'acide désoxyribonucléique (ADN) dans le cadre de la justice pénale, Strasbourg.

160. COMMISSION DE RÉFORME DU DROIT DU CANADA, op. cit., note 56.

161. COMMISSAIRE À LA PROTECTION DE LA VIE PRIVÉE DU CANADA, Le dépistage génétique et la vie privée, Ministère des approvisionnements et Services Canada, Ottawa, 1992, pp. 50-59. 
Outre les restrictions énumérées par le droit interne ${ }^{162}$, le consentement du suspect doit être requis.

La protection de la vie privée se traduira par une utilisation restreinte à la partie non codante de l'ADN (la finalité des empreintes génétiques n'est pas de constituer une carte génétique) et par une limitation de constitution des banques de données et une protection des données ${ }^{163}$. Quant aux échantillons, ils ne peuvent être utilisés que pour les affaires pour lesquelles ils ont été prélevés. La conservation pour des actions ad futurum, n'ayant aucun lien direct avec l'infraction reprochée, est prohibée. Cela suppose la destruction des échantillons des personnes innocentées. Cependant, on peut entrevoir dans une recommandation ${ }^{164}$ que la conservation des échantillons ou des résultats de l'analyse d'ADN de personnes non condamnées est envisagée dans les cas d'une infraction où la sûreté de l'Etat est mise en cause.

\section{---- L'égalité des parties}

Un accès égal aux méthodes de l'ADN comme un élément de preuve doit être admis aussi bien pour la poursuite que pour la défense; il en sera de même de l'accès aux informations obtenues qui fut considéré, depuis l'arrêt Stinchcombe $e^{165}$, comme une composante indispensable du droit à une défense pleine et entière.

162. Voir les articles 256 à 258 du Code criminel et l'article 2 de la Loi sur l'identification des criminels, précités, note 124 .

163. Des informations limitées seraient accessibles seulement à partir d'une banque de données nationale dont l'accès serait réservé à un nombre restreint de personnes légalement autorisées et dans le cadre de procédures officielles bien spécifiées par la loi.

164. CONSEIL DE L'EUROPE, Rec. R (92) précitée, note 159.

165. R. c. Stinchcombe, (1991) 130 N.R. 277. 


\section{--- La qualité de l'information génétique}

L'agrément des laboratoires et l'encadrement de la technique sont considérés comme une nécessité. Selon les recommandations citées plus haut, l'agrément ne peut être donné qu'à des laboratoires ou des institutions répondant aux critères d'intégrité scientifique et de compétence professionnelle. Quant à l'encadrement, il sera mis en oeuvre à partir des procédures suivantes : un protocole de contrôle (vérification de la provenance de l'échantillon et méticulosité dans l'étiquetage), un contrôle de l'analyse au cours des diverses étapes, un autocontrôle par les techniciens et par un contrôle extérieur des laboratoires au moins une fois l'an.

Tous ces principes doivent reposer, non seulement sur la communication de l'information et sur la formation des intervenants, c'est-à-dire des utilisateurs de la méthode, mais aussi sur la prise de conscience de toute la société.

\subsection{La communication}

En raison des enjeux éthiques de la preuve d'identification par ADN, tous les acteurs sociaux doivent être conviés à un débat public. Et pour ce faire deux étapes sont nécessaires : la formation et l'information.

La formation doit concerner non seulement les scientifiques (l'accélération prodigieuse des techniques et la découverte de nouveaux gènes incitent à une mise à jour régulière des connaissances et à une attitude de responsabilité), les juristes appelés à utiliser cette nouvelle preuve et à en évaluer la force probante ainsi que le grand public.

Dans la société où les repères traditionnels s'effritent et où les imaginaires prédominent face à la science, l'information et l'éducation s'avèrent impératives. En effet le plus grand danger résulte de l'ignorance, du manque de connaissance et du manque de transfert de connaissance. La société ne doit pas s'enfermer dans un enthousiasme débordant. Elle doit estimer les répercussions immédiates et lointaines, les conséquences juridiques et éthiques inhérentes à l'utilisation de la méthode des analyses génétiques. Il faut aussi mettre l'accent sur l'information adéquate du public, et l'inciter au dialogue et à la responsabilisation, car l'utilisation des analyses génétiques relèvent de la 
responsabilité de la société toute entière. Le travail d'information concerne également les médias qui doivent donner des renseignements objectifs et précis.

Des dispositifs législatifs faciliteraient certes l'utilisation de la preuve d'identification puisque la loi peut fixer des limites pour éviter des abus et concilier le respect des valeurs fondamentales.

\section{2- $\quad$ Assises de droit positif}

Il nous semble important d'indiquer s'il existe des statuts encadrant la preuve d'identification par ADN en droit comparé afin de cerner la protection juridique adéquate en droit pénal canadien. Par conséquent, un bref examen de l'expérience législative étrangère paraît indispensable.

\subsection{Droit comparé}

Les législations encadrant la preuve d'idendification par ADN sont quasi inexistantes; seuls les États-Unis ont une avance dans ce domaine : ils ont édicté des lois autorisant l'utilisation des analyses génétiques dans des enquêtes criminelles ainsi que l'entreposage de données génétiques dans des banques de données ${ }^{166}$. Ainsi huit États ${ }^{167}$ ont adopté des législations concernant l'admissibilié des tests d'ADN et vingt-deux ${ }^{168}$ ont légiféré pour autoriser un prélèvement obligatoire d'échantillons de sang en vue de l'identification génétique. En France, le projet de loi $n^{o} 2599^{169}$, s'inspirant de l'avis du Comité Consultatif National d'Éthique, a consacré un paragraphe à l'utilisation de la preuve génétique. Ce projet pose le principe d'un encadrement législatif de cette preuve et $\mathrm{y}$ subordonne son utilisation à une autorisation judiciaire. En

166. Lorne T. KIRBY, op. cit., note 64, pp. 199-201; au total on peut dénombrer, en octobre 1993, 20 législations.

167. Ce sont les États de l'Indiana, de la Louisiane, du Maryland, du Minnesota, du Nevada, du Tenessee, de la Virginie et du Wisconsin.

168. L'Arizona, la Californie (ici, la législation est intégrée au Code pénal, voir l'article 290.2), le Colorado, la Floride, la Georgie, l'État d'Hawaï, l'Ilinois, l'Indiana, l'Iowa, le Kansas, le Kentucky, le Michigan, le Minnesota, le Missouri, le Nevada, l'Oklahoma, l'Oregon, le Dakota du Sud, le Tennessee, la Virginie, l'État de Washington, le Wisconsin.

169. Projet de loi relatif au corps humain et modifiant le code civil, J.O., doc. Assemblée Nationale, $1992, \mathrm{n}^{\circ} 2599$, pp. 13-15. 
Allemagne, le ministère de la Justice prépare un projet de modification du Code de procédure pénale sur l'utilisation des analyses génétiques lors des procès criminels ${ }^{170}$; l'usage des échantillons biologiques comme éléments de preuve devant les tribunaux criminels sera ainsi réglémenté. Les autorités néerlandaises ont aussi présenté un projet de loi autorisant le prélèvement du sang ou de tout échantillon biologique en vue d'une analyse génétique, sous réserve de l'exigence par la cour suprême d'une base légale avant l'emploi d'une telle technique $^{171}$. Au Canada, la loi est muette pour le moment, mais n'est-il pas temps de réagir au moment où cette preuve se bouscule devant les tribunaux? ${ }^{172}$ La technologie, en matière de cueillette de preuves, n'est pas figée et requiert de nouvelles réponses de la part du législateur.

\subsection{Proposition d'une législation au Canada}

Les règles de l'utilisation de la preuve d'identification par ADN sont pour le moment déduites des décisions des tribunaux. D'entrée de jeu, on pourrait se laisser convaincre par le statu quo, mais en l'absence de toute loi, on assistera à des pratiques abusives. De même, on pourrait interdire purement et simplement cette méthode qu'on jugerait perméable aux atteintes aux droits de l'individu; cette position ne serait pas raisonnable et l'administration efficace de la justice en pâtirait. Une solution adéquate consisterait à fixer un cadre général pour l'utilisation de ce moyen de preuve en prenant diverses mesures assorties de sanctions pénales et en mettant en place des commissions spécialisées de vérification. Ces mesures doivent être inspirées par des préoccupations de justice, n'évacuer aucune considération morale, et être modérées. Certes, les normes ne sont pas parfaites, mais elles doivent viser une qualité adéquate. Elles doivent être des guides, des outils fonctionnels tout en demeurant perfectibles au gré de l'évolution de la technologie et de la connaissance. Les pouvoirs exorbitants accordés aux policiers par le Projet de Loi C109 ${ }^{173}$ permettraient

170. N. LENOIR, op. cit., note 9, p. 399.

171. G. CORTES, «Le droit néerlandais», (1993) 63 Revue Internationale de droit pénal, 285.

172. À ce jour, on peut compter plus d'une centaine de témoignages rendus par des experts devant nos tribunaux.

173. Loi modifiant le Code criminel en matière de surveillance électronique et d'interception des communications par téléphone cellulaire (Projet de loi C-109) Art. 487.01(1) : «Un juge de la cour provinciale, un juge de la cour supérieure criminelle ou un juge au sens de l'article 552 peut décerner un mandat par écrit autorisant un agent de la paix, sous réserve du présent 
d'envisager l'utilisation d'une telle preuve; cette solution est peut-être valable, mais le droit positif ne saurait combler le vide juridique et faire face à des situations critiques, car la génétique relève d'un domaine où le pouvoir offert est «dangereux» et écrasant. Il y a aussi le piège de déviation de l'information soulevé par la création de banques de données ou de fichiers. Il faut limiter les données qui seront accessibles aux tiers. Ainsi, la preuve d'identification par ADN doit être encadrée par une législation pour éviter les abus. Le Code criminel ou la Loi sur la preuve ${ }^{174}$ devraient être modifiés pour poser les limites juridiques spécifiques à l'utilisation de la preuve d'identification par ADN. L'amendement pourrait aussi viser la Loi sur l'identification des criminels ${ }^{175}$ en y incluant, par exemple à l'article 2 (1), une disposition qui permettrait des prélèvements d'échantillons biologiques. Cependant, le législateur doit tenir compte de la proportionnalité entre les atteintes aux droits de l'accusé et les avantages que peut retirer la justice. ${ }^{176}$ Cette loi doit protéger les valeurs fondamentales comme le droit à l'intégrité, le droit à l'intimité, le droit à la nondiscrimination etc... Elle devrait reprendre les grandes recommandations telles l'utilisation de la partie non-codante de l'ADN pour l'identification en matière criminelle; l'usage restrictif de la preuve obtenue (crimes graves et dans des procédures judiciaires, ce qui suppose l'autorisation du juge pour les prélèvements d'échantillons); la limitation des analyses d'échantillons aux causes pour lesquelles les échantillons ont été requis et pour les finalités ordonnées; le respect du droit à la contre-expertise par le prélèvement d'une quantité appréciable d'échantillons biologiques; l'accomplissement des analyses par des laboratoires agréés; le contrôle rigoureux de la technique et des banques de données; la restriction de l'accès à l'information à certaines personnes bien identifiées et habilitées; la destruction des données génétiques des personnes

article, à utiliser un dispositif ou une technique ou une méthode d'enquête, ou à accomplir tout acte qui est mentionné, qui constituerait sans cette autorisation une fouille, une perquisition ou une saisie abusive à l'égard d'une personne ou d'un bien...»

174. Loi sur la preuve au Canada. S.R.C 1970, c. E-10

175. Loi sur l'identification des criminels. S.R.C. 1970, c. I-1.

176. Voir l'arrêt Oakes, précité, note 116, qui à propos de la raisonnabilité de la règle de droit qui peut restreindre les droits et libertés garantis par la Charte canadienne dans son article 1, énonce un test de proportionnalité à trois composantes à savoir : «a) la présence d'un lien rationnel entre la mesure proposée et l'objectif à atteindre; b) malgré la présence de cette rationalité, l'atteinte au droit garanti par la Charte sera la plus minime possible, c) proportionnalité entre les effets de la mesure proposée et l'objectif identifié comme suffisamment important». 
innocentées dans les banques de données et l'élimination des échantillons sauf si la sûreté de l'État est en cause. Dans tous les cas, les échantillons et les données pourraient être conservés pendant un délai fixé par la loi. Toute infraction pourrait donner lieu à une responsabilité pénale.

\section{CONCLUSION}

À première vue, notre étude révèle que l'un des principaux écueils à l'admissibilité de la preuve d'identification par ADN est lié au problème des probabilités statistiques et à la population de référence. Mais force nous est de constater que les atteintes qui peuvent découler de la cueillette des échantillons et de l'utilisation des données sont plus graves. En effet, les analyses génétiques, même si elles ne créent pas un véritable pouvoir scientifique, peuvent mettre en péril un nombre important de droits fondamentaux et, en conséquence, le respect de la dignité humaine. Nous suggérons d'introduire dans la législation nationale des mesures coercitives qui pourraient limiter les abus. Il faut mettre en place une réglementation qui répondra mieux aux exigences de la liberté et de la démocratie et assurera la protection de l'information génétique. Cependant, toute réglementation exclusivement nationale risquerait de s'avérer inefficace et dangereuse dans la pratique; en effet, la nécessité de favoriser la circulation libre des données pour des raisons économiques et pour l'efficacité de la lutte contre la criminalité soulève des questions qui imposent de mettre en place des dispositifs appropriés et coordonnés. Il est inéluctable de progresser vers une harmonisation des réglementations et des accords de type international. Sans nul doute, une pareille approche paraît plus réaliste dans la lutte contre la criminalité et la protection de la dignité humaine. 